\title{
Sox11 gene disruption causes congenital anomalies of the kidney and urinary tract (CAKUT)
}

\section{Short title: SOX11 and CAKUT}

Yasmine Neirijnck $^{1{ }^{*}}$, Antoine Reginensi ${ }^{1 *}$, Kirsten Y Renkema ${ }^{2}$, Filippo Massa ${ }^{1}$, Vladimir M. Kozlov ${ }^{1}$, Haroun Dhib $^{1}$, Ernie MHF Bongers ${ }^{3}$, Wout F Feitz ${ }^{4}$, Albertien M van Eerde ${ }^{2}$, Veronique Lefebvre ${ }^{5}$, Nine VAM Knoers ${ }^{2}$, Mansoureh Tabatabaei $^{6}$, Helen McNeill ${ }^{7}$, Franz Schaefer ${ }^{6}$, Michael Wegner ${ }^{8}$, Elisabeth Sock ${ }^{8}$, Andreas Schedl $^{1}$

* These authors contributed equally to this work.

${ }^{1}$ Univ. Nice Sophia Antipolis, Inserm, CNRS, iBV, 06100 Nice, France

${ }^{2}$ Department of Genetics, Center for Molecular Medicine, University Medical Center Utrecht, Utrecht, The Netherlands

${ }^{3}$ Department of Human Genetics, Radboud university medical center, Nijmegen, The Netherlands

${ }^{4}$ Department of Urology, Radboudumc Amalia Children's Hospital, Radboud university medical center, Nijmegen, The Netherlands

${ }^{5}$ Department of Cellular \& Molecular Medicine, Cleveland Clinic Lerner Research Institute,

Cleveland, $\mathrm{OH} 44195$, USA

${ }^{6}$ Division of Pediatric Nephrology, Heidelberg University Center for Pediatrics and Adolescent Medicine, , Heidelberg, Germany

${ }^{7}$ Lunenfeld-Tanenbaum Research Institute, Mount Sinai Hospital, Toronto, Canada.

${ }^{8}$ Institute of Biochemistry, University Erlangen-Nuernberg, Germany

\begin{tabular}{|c|c|}
\hline Corresponding author: & $\begin{array}{l}\text { Andreas Schedl } \\
\text { Inserm UMR1091 } \\
\text { Centre de Biochimie } \\
\text { Parc Valrose } \\
06108 \text { Nice } \\
\text { France } \\
\text { Tel.: ++33492076401 } \\
\text { FAX: ++33492076402 } \\
\text { Email: Schedl@unice.fr }\end{array}$ \\
\hline
\end{tabular}

4574 words 


\begin{abstract}
Congenital abnormalities of the kidney and the urinary tract (CAKUT) belong to the most common birth defects in human, but the molecular basis for the majority of CAKUT patients remains unknown. Here we show that the transcription factor SOX11 is a crucial regulator of kidney development. SOX11 is expressed in both mesenchymal and epithelial components of the early kidney anlagen. Deletion of Sox11 in mice causes an extension of the domain expressing Gdnf within rostral regions of the nephrogenic cord and results in duplex kidney formation. On the molecular level SOX11 directly binds and regulates a locus control region of the protocadherin B cluster. At later stages of kidney development, SOX11 becomes restricted to the intermediate segment of the developing nephron where it is required for the elongation of Henle's loop. Finally, mutation analysis in a cohort of patients suffering from CAKUT identified a series of rare SOX11 variants, one of which interferes with the transactivation capacity of the SOX11 protein. Taken together these data demonstrate a key role for SOX11 in normal kidney development and may suggest that variants in this gene predispose to CAKUT in humans.
\end{abstract}

\title{
Key words
}

Sox11, CAKUT, kidney induction, duplex kidneys, nephron 


\section{Introduction}

With an incidence of 1 in 500 , congenital abnormalities of the kidney and urinary tract (CAKUT) belong to the most common defects in the unborn child. CAKUT unites a diverse group of disease entities including renal agenesis, hypoplasia and dysplasia, as well as defects affecting the ureter ${ }^{1}$. Despite its importance as the major cause of renal failure in children, the molecular basis of CAKUT is unknown in as many as $80 \%$ of cases 2 .

CAKUT is rooted in defective kidney development. In the mouse embryo, metanephric development commences at around embryonic day (E)10 with the specification of the metanephric mesenchyme (MM) at the caudal end of the nephrogenic cord ${ }^{3}$. MM cells release the glial-derived neurotrophic factor GDNF, which serves as an inductive signal that initiates ureteric budding from the Wolffian duct (WD). At the molecular level, GDNF binds at the surface of WD cells to its tyrosine kinase receptor RET and induces ureteric bud (UB) growth and branching ${ }^{4}$. The UB subsequently invades the MM to undergo a series of dichotomous branching events giving rise to the ureteric tree. Induction of the UB outgrowth must be tightly controlled, as failure of UB induction leads to renal agenesis ${ }^{5}$. Conversely, ectopic signaling causes supernumerary UBs that can lead to duplex kidneys, a condition that is frequently associated with hydronephrosis and hydroureter ${ }^{6,7}$.

Signals released from the ureter induce mesenchymal cells to epithelialize through mesenchymal to epithelial transition (MET) ${ }^{8}$ and the resulting renal vesicle (RV) undergoes further patterning events and morphogenetic movements to form the differentiated nephron, the functional unit of the kidney. Nephrons are highly segmented with the glomerulus, proximal tubule, Henle's loop and distal tubule serving distinct functions and expressing a specific set of marker genes.

The Sox family comprises 20 genes that encode transcription factors involved in a diverse range of developmental and pathological processes ${ }^{9}$. Based on the phylogenetic homology of their HMG box DNAbinding domain Sox genes are categorized into eight groups ${ }^{10}$. We have previously reported an important function for Sox8 and Sox9 in kidney development ${ }^{11}$ and renal repair ${ }^{12}$. Members of the SoxC group, Sox4, Sox11 and Sox12 are also expressed in kidney development and Sox 4 has been suggested to play a role in nephron endowment ${ }^{13}$. Sox 11 knockout analysis has revealed its requirement for the development of a variety of organs ${ }^{14}{ }^{15}$, but a potential involvement of this gene in kidney development has not yet been reported.

Here, we show that SOX11 fulfills essential regulatory functions during early kidney induction, as well as nephron maturation in mice. Moreover, the identification and characterization of rare human SOX11 gene variants in CAKUT patients further suggests this gene may also contribute to human kidney disease. 


\section{Results}

\section{SoX11 is required for normal development of the urogenital tract}

While previous studies have already reported Sox11 to be expressed in kidney development ${ }^{13,14,16}$, a detailed analysis, in particular at early stages of kidney induction, has been missing. Immunostaining at E11 revealed relatively broad SOX11 expression in the mesenchyme of the nephrogenic cord, the UB and the Wolffian duct (WD) (Figure 1A and Suppl. Figure 1). At later stages, SOX11 expression was maintained in the epithelial and mesenchymal compartments (ureter, UB and cap mesenchyme, respectively) of the developing kidney (Figure 1A), but was absent from FoxD1-positive stromal cells (Figure 1B). Upon MET, robust staining was observed throughout the newly formed RV, which by the S-shaped body stage was strongest within the intermediate segment (future Henle's loop) (Figure 1C). Upon differentiation, expression persisted at low levels in elongating nephron tubules (Figure 1A, right panel), but no signal was detected in fully differentiated cells or adult kidneys (Figure 1D). Similarly, to kidney development, Sox11 was found broadly expressed at early stages (E12.5) of urethra development, but was no longer detectable from E14.5 onwards (Fig.1E and data not shown).

To analyze a potential role of SOX11 in urogenital development, we employed a previously published knockout allele that in the homozygous state results in perinatal death due to heart failure ${ }^{14}$. Analysis of dissected urinary tracts in E18.5 embryos revealed a range of defects, including unilateral and bilateral duplex kidneys, hydronephrosis, hydroureter and abnormally positioned ureters (Figure 2, Table 1 and data not shown). Interestingly, duplex kidneys were also seen in a small proportion of heterozygous mutants $(5.1 \%)$ indicating Sox11 haploinsufficiency (Figure 2B, E, I and Table 1). Histological analysis revealed that duplex kidneys were associated with an ectopic ureter that connects to the bladder in a position caudally to that of the normal site (Figure $2 \mathrm{H}$ ). In addition to kidney and ureter defects, a proportion of Sox11 null mutants also displayed genital tract defects, including misplaced ovaries and undescended testes (Suppl. Figure 2). When present, these defects were always found in association with duplex kidneys, suggesting that the abnormal position of the gonads might be linked to renal abnormalities.

\section{Sox11 restricts ureter budding to a single site}

The occurrence of duplex kidneys in Sox11 mutants suggested an early developmental defect. Indeed, dissection of kidney rudiments at E11.5 revealed two UBs that, when cultured, developed into two kidneys (Suppl. Figure 3). Ureteric budding is primarily regulated by GDNF/RET signaling ${ }^{3}$. To test whether ectopic budding may be caused by a disruption of this signaling pathway we performed qPCR and wholemount in situ hybridization (ISH) analysis on E10.5 and 11.5 embryos. Quantitative PCR analysis of Ret and Gdnf expression did not reveal any significant change of expression levels in wildtype and mutant embryos (Suppl. Figure 4A\&B). As expected, Ret expression was found within the mesonephric duct and the T-shaped branched ureter in wildtype embryos (Figure 3A). In homozygous Sox11 mutants, the overall Ret expression pattern was unchanged, although it highlighted the second UB emerging slightly rostrally to the normal induction site (Figure 3B).

In contrast to the epithelial Ret expression, Gdnf is expressed in mesenchymal renal progenitor cells. In wildtype mice, low levels of Gdnf can be found already at E9.5 along the entire length of the mesonephric mesenchyme, but by $\mathrm{E} 10.75$ expression becomes restricted to the MM at the caudal end of the nephrogenic 
cord (for review see ${ }^{5}$ ). Strikingly, homozygous mutants displayed a dramatic rostral extension of the Gdnf expression domain, when compared to wildtype embryos of the same stage (Figure 3C,D and Suppl. Figure 4C,D). More anterior staining was also seen when using other MM specific markers such as Six2 (Figure 3E,F) indicating a rostral expansion of MM cells rather than a simple upregulation of Gdnf in Sox11 mutant embryos. Taken together these data show that SOX11 is required to restrict Gdnf expressing cells to the caudal end of the nephrogenic cord.

\section{SOX11 regulates the protocadherin $\beta$ genes by directly binding to its cluster control region.}

SOX11 is foremost a transcriptional regulator and loss of function is likely to affect the expression of downstream target genes. Formation of ectopic UBs has been reported previously in mouse mutants including Gata $3^{17}$, Sprouty ${ }^{18}$, Bmp $4{ }^{19}$, Foxc $1 / 2^{7}$, Robo2 and its receptor Slit ${ }^{6}$. ISH expression analysis showed no significant changes for these genes (Suppl. Figure 5 and data not shown) suggesting that SOX11 acts through independent molecular pathways.

To obtain an unbiased view on genes whose expression depend on SOX11 we performed microarray analysis on RNA isolated from the caudal region of E10.75 wildtype and mutant nephrogenic cords. 281 probe sets presented statistically significant changes ( 76 up, 205 down; FDR $<0.1$ ) with 68 of these (13 up and 55 down) showing more than 1.5 fold up-/down-regulation (Supplementary data 1). Expression of genes known to be involved in duplex kidney formation were not significantly changed in mutant mice, thus further corroborating our in situ hybridization analysis.

Bioinformatic analysis using the DAVID tool ${ }^{20}$ revealed a 144 -fold enrichment of the protocadherin $\beta$ annotation cluster ( $p=6.3 e-18)$ (Supplementary data 2$)$ with 17 out of 22 genes being downregulated in Sox 11 mutants (Figure 4A). Protocadherin $\beta$ genes are organized in a cluster on mouse chromosome $18^{21}$ and mapping the fold-change of probe sets along the chromosome showed a compelling reduction of expression of the entire gene family (Figure 4B). Previous analysis had identified a cluster control region (CCR) mapping $320 \mathrm{~kb}$ downstream of the protocadherin $\beta$ locus that seems to be required for the expression of the 22 Pcdhb genes ${ }^{22}$. To test whether SOX11 might directly bind the CCR, we performed ChIP-qPCR experiments on E14.5 wildtype kidneys. Strikingly, an 8-fold enrichment of chromatin precipitated with SOX11 (over IgG) was found at hypersensitive site HS19-20 of the CCR (Figure 4C). No such enrichment could be detected with primers for a negative control region, located in the 3'UTR region of Cd24a gene. We conclude that direct binding of SOX11 to the locus control region is essential to provide high levels of expression of the PcdhB gene cluster.

\section{Nephron segment defects in Sox11 mutants}

The dynamic expression pattern of Sox11 during nephron formation prompted us to analyze a potential function of this gene at later stages of kidney development. Examination of E18.5 kidney sections revealed hypo-dysplastic kidneys with an apparent reduction of epithelial components and an increase of stromal tissue in the medulla (Figure 5A-B'). A proportion of mice also displayed mild proximal tubule dilatation, but this phenotype was not $100 \%$ penetrant (data not shown). ISH experiments revealed persistent expression of proximal (S/c5a2 and S/c5a1), distal and connecting tubule (S/c12a3 (Ncc)) markers, but dramatically shortened Henle's loops (SIC12a1 (Nkcc2) (Figure 5C-J), which was also reflected by reduced expression of 
Irx1 and Irx2 (Suppl. Figure 6A-D). To obtain a more quantitative evaluation of segment specific changes, we next counted the number of structures/cells highlighted by specific markers. Glomerular numbers, as defined by the expression of podocin (NPHS2), were unchanged in mutant kidneys indicating that loss of Sox11 does not interfere with nephron induction and glomerular maturation (Figure 6A-C). Immunostaining with antibodies detecting LTL (proximal tubule=PT) showed a small decrease, which however did not reach statistical significance (Figure 6D-F). By contrast, the number of cells positive for markers identifying Henle's loops (Tamm-Horsfall protein THP) and - to a lesser extent - the distal convoluted tubule (NCC) were significantly reduced indicating a particular requirement for SOX11 for these segments (Figure 6G-L). Interestingly, numbers of cells positive for Henle's loop and distal tubule markers were also reduced in Sox11 heterozygous mutants, suggesting that SOX11 acts in a dosage-sensitive manner also during nephron maturation. Analysis of early nephron patterning markers (WT1, PAX2, JAG1, HNF1 $\beta$, BRN1, SOX9 and Papss2) revealed normal expression (Suppl. Figure 6E-H).

Previous studies have shown that elongation of Henle's loops depends on collecting duct derived Wnt7 $\mathrm{b}$ that induces canonical $\beta$-catenin signaling in surrounding stromal cells resulting in the activation of Lef1 ${ }^{23}$. qPCR analyses revealed a mild increase of the Wnt inhibitor Dkk1 in Sox11 mutant (Suppl. Figure 7C). However, ISH, immunofluorescence and qPCR analyses did not reveal significant changes in Wnt7b, Lef1 and Axin2 expression, thus ruling out regulation of this pathway by SOX11 (Suppl. Figure 7C-D). Moreover, mitotic figures (phospho-histone $\mathrm{H} 3$ ) revealed no significant changes in the proliferation rate of early nephron structures nor in elongating loops of Henle (Suppl. Figure 7A-B). Similarly, apoptotic figures were unchanged between wildtype and controls (data not shown).

\section{Analysis of SOX11 in a cohort of human CAKUT patients}

Urogenital tract defects observed in Sox11 null mice are reminiscent of congenital abnormalities observed in human CAKUT patients. To determine whether SOX11 variants may be associated with CAKUT, we screened the coding sequence of SOX11 (NM_003108.3) in a cohort of 560 patients (Table S1). A total of 6 heterozygous variants were detected in 6 patients, including 2 silent point mutations, 3 missense point mutations and 1 insertion of 12 nucleotides resulting in an in-frame insertion of 4 amino-acids (Figure 7). One patient (\#5) with posterior urethral valves and kidney hypoplasia showed two SOX11 variants, including a 12bp insertion and a missense mutation.

Comparison of our variants with online databases (1000 genomes project ${ }^{24}, \mathrm{NCBI}$ database of genetic variation $\mathrm{dbSNP}^{25}$, ExAC Browser ${ }^{26}$ ) revealed the presence of 4 variants (c.63G>T, c.257G>T, c.658G>A and c.1131C>T (not validated)) in previously sequenced populations (Table 2). The other two variants (c.995C $>\mathrm{T}$, c.1063_1064insAGCGGCAGCAGC) were absent from public databases. Online mutation prediction using RegRNA 2.0 software ${ }^{27}$ suggested that the silent C.1131C>T variant may introduce a novel splice donor site (Suppl. data file 3). SIFT analysis (http://sift.jcvi.org/) did not reach a high enough score, but both PolyPhen-2 (genetics.bwh.harvard.edu/pph2) and Mutation tasting (http://www.mutationtaster.org/) considered several variants as damaging. Of particular interest is variant c.257G>T (p.R86L), as it affects the HMG box DNA binding domain, which has been highly conserved throughout evolution.

SoxC class proteins can act as classical transcription factors that bind to DNA and activate downstream target genes. To test whether the variants would interfere with transactivation we recreated expression vectors and 
co-transfected them with a luciferase reporter plasmid of the Gdf5 promoter, a proposed downstream target of SOX $11^{28}$. Most variants had no dramatic effect on reporter gene expression (Supp. Figure 8). One exception was the insertion mutation c.1063_1064insAGCGGCAGCAGC, which completely abrogated reporter plasmid activation.

\section{Discussion}

Kidney development is a highly complex process that requires the orchestrated action of transcription factors to ensure proper induction, proliferation and differentiation. SOX genes are one class of factors that have already previously been implicated in kidney development. While SOX8 and SOX9 are required for ureter branching ${ }^{11}$, SOX4 has been suggested to be required for nephron endowment ${ }^{13}$. Here we have identified SOX11 as a novel player in kidney formation that appears to act during metanephros induction and nephrogenesis.

The first step of kidney development involves specification of the MM within the nephrogenic cord with Gdnf and Six2 often being used as molecular markers for this compartment. Both of these genes are expressed in Sox11 mutants indicating that specification occurs normally in the absence of this gene. Ureter induction relies on GDNF/RET signaling and alterations in this pathway can lead to renal agenesis or ectopic budding. Overall expression levels of Ret and Gdnf appeared unaffected in mutants when analyzed by qPCR. ISH analysis, however, revealed a dramatic rostral extension of the Gdnf expression domain, which could be explained by several mechanisms: 1) A requirement for SOX11 to suppress Gdnf expression: this seems unlikely, as SOX11 expression is also found in MM and thus overlaps with Gdnf and Six2; 2) lack of apoptosis in rostral domains; 3) disrupted cell migration of rostrally located MM precursors towards the caudal end. Although directed migration of mesenchymal cells towards the caudal end of the intermediate mesoderm has not been demonstrated so far, two previous studies using Wnt5a/Ror2 knockout mice have suggested that such a migration may occur ${ }^{29,30}$. Several lines of evidence from our own studies further support this hypothesis. Firstly, the extended expression domain in the rostral mesonephros is accompanied by a thinning of the $G d n f^{+}$and Six $2^{+}$domain in the caudal region (Figure 3 ), an observation that is consistent with a disrupted migration of MM cells. Secondly, our microarray analysis in E10.75 Sox11 mutants revealed a dramatic loss of molecules involved in cell adhesion and cell migration, such as the protocadherin- $\beta$ cluster and members of the semaphorin signaling pathway (Sema6C, Dpys/5). While duplex formation in mutant mice for these genes ${ }^{31,32}$ nor the Pcdhb locus control region ${ }^{22}$ have not been reported, mutations in the semaphorin family member Sema3a leads to increased ureter branching ${ }^{33}$. We therefore hypothesize that the combined reduction of these genes causes defects in cell adhesion and migration. A role for SOX11 as a regulator of cellular migration as been previously shown in mesenchymal stem cells ${ }^{34}$. Further experiments will need to be performed to demonstrate active migration of Gdnf positive mesenchymal cells towards the caudal end of the nephrogenic cord, as a potential mechanism required for the formation of a bona fide metanephric mesenchyme. If our model turns out to be correct, mesenchymal cell migration would mirror the active migration of epithelial cells within the mesonephric duct that has been shown previously to be essential for proper kidney induction ${ }^{35,36}$. While expression of SOX11 is maintained in the ureter and MM throughout development, deletion does not seem to affect ureter branching and based on glomerular counts Sox11 mutants develop the normal number of nephrons. This finding is somewhat surprising given that previous studies have suggested an important function for SOX11 in regulating Wnt4 during nephron formation at least in Xenopus embryos ${ }^{37}$. The persistent nephrogenesis could potentially be explained through functional redundancy with other members of the SOXC 
gene family (SOX4 and SOX12). By contrast, Sox11 seems to have a unique role during nephron formation and mutants display dramatically shortened Henle's loop, while other segments were only mildly affected. Nephron patterning, occurs at a very early stage during morphogenesis and several key genes have been identified in recent years ${ }^{38,39}$. Molecular analysis, revealed the expression of all segment specific markers indicating that initial patterning of the nephron occurs in Sox11 mutant mice. Assignment of segment identity involves a careful balance between $\beta$-catenin, Notch and BMP signaling, with distal/intermediate segments showing the highest $\beta$-catenin activity ${ }^{38}$. Since the proliferation rate in both S-shaped bodies and elongating Henle's loops was unchanged in mutants, we can speculate that the initial number of progenitors within the intermediate segments may be reduced. Proving this hypothesis would require a careful 3-D analysis of a precisely defined nephron stage, which is difficult due to the highly dynamic nature of nephrogenesis.

During fetal life, gonads are anchored in the abdominal wall by the cranial suspensory ligament (CSL) and the gubernaculum, at their cranial and caudal poles, respectively. Sex dimorphic regression/development of both CSL/gubernaculum causes testicular descent whereas ovaries stay localized at the lower poles of the kidneys, processes controlled by testicular hormones ${ }^{40-42}$. Given the fact that the position of both, testes and ovaries are affected in Sox11 mutant mice, absence of male hormones appears to be unlikely the cause of these defects. Alternatively, Sox11 may have a hormonal-independent role within CSL and/or gubernaculum to allow their proper morphogenesis. A third possible explanation involves interdependence of urinary and genital tracts defects. Several reports have shown abnormal localization of the gonads in mouse mutants with ureter malformations ${ }^{7,18,43}$ with failure of gonadal duct/ureter separation due to common nephric duct (CND) persistence. Interestingly, ectopic testes in Sox $11^{-/}$mice is associated with a hydroureter connecting to the vas deferens (Suppl Figure 2D'). Future work investigating the roles of Sox11 in the development of gonads, CSL/gubernaculum and CND will be needed to identify in which compartment this gene is required for proper genital tract development.

The incomplete penetrance of the phenotype is in line with observations made for CAKUT in humans. Indeed, disease-causing mutations are often transmitted from phenotypically normal parents to their children, thus highlighting the complexity of the genetics and a potential contribution of stochastic and environmental factors in complex diseases like CAKUT ${ }^{44}$. The fact that defects could be observed in a proportion of heterozygote mice supports gene dosage sensitivity and is in line with the type of genetic alteration associated with CAKUT in human patients. The broad range of urogenital defects observed in Sox11 mutant mice also corresponds with the observations of diverse phenotypes made in familial CAKUT.

SOX11 gene mutation analysis revealed a 12bp insertion and five point mutations in a large cohort of CAKUT patients. These patients display different types of urogenital tract malformations which are recapitulated in Sox11 mouse model, namely duplex kidneys, renal hypoplasia, maldescendant testis and UPJ obstruction. Strikingly, four out of the five male patients suffer from ureter malformations. In mouse, SOX11 is expressed in early urogenital sinus, which is in correlation with its potential role in ureteral development.

Although the pathogenic significance of the identified variants is uncertain at present, the complete absence, or very low frequency of these genetic variants in public databases, further supported by in silico predictions may suggest that at least some of them could be involved in the development of CAKUT. Functional analysis in transfection assays confirmed the disruptive nature of one variant for transcriptional activity of SOX11. Of interest, this variant has been recently identified in a patient suffering from coloboma ${ }^{45}$, thus further implicating 
an important role for SOX11 disruption in human disease. It is challenging to determine in vitro whether the other variants identified in this study contribute to disease etiology. Modeling the mutations in vivo using CRISPR/Cas9 approaches may address this problem.

In conclusion, our study has identified SOX11 as a crucial regulator of kidney development. SOX11 restricts Gdnf expressing cells to the caudal part of the nephrogenic cord, controls single UB outgrowth and is required for proper nephron formation. Although our study does not unequivocally proof an involvement of SOX11 in human CAKUT, the identification of rare variants in patients in combination with the phenotype observed in our mouse model makes it a strong candidate for human CAKUT disease.

\section{Materials and methods}

\section{Mice}

All animal work was conducted according to national and international guidelines and has been approved by the local ethics committee (NCE/2011-19). Sox11 knockout mouse strain was described previously ${ }^{14}$. Sox11 knockout mice were maintained on a mixed B6D2F1 genetic background. All comparisons were done between littermates of the same strains. Routine genotyping of mice was carried out by PCR as previously described 11.

\section{Glomeruli and cell number quantification}

Paraffin sections of 6 independent E17.5 embryos for each condition (control, heterozygote and Sox11 knockout) were processed in immunofluorescence with antibodies against WT1 and Podocin/NPHS2 or WT1 and Nephrin/NPHS1. For segment specific cells number quantification, paraffin sections of 3 independent E17.5 embryos from the 3 different conditions were stained for LTL, THP or NCC. Pictures were taken with an Axiocam Mrm camera (Zeiss) and processed with ImageJ. Glomeruli and cells were counted manually by a single blind operator. Statistical analysis was performed using Student's T-test.

\section{Proliferation assay}

For elongating Henle's loop analysis, mice were injected with BrdU intraperitoneally on 17.5 day of pregnancy, and sacrificed 90 minutes later. Embryo sections were stained for BrdU, BRN1, LTL and DBA and cells were counted using the Cell Counter plugin in the Fiji software. The total number of $\mathrm{BrdU}^{+} / \mathrm{BRN} 1^{+} / \mathrm{LTL}^{-} / \mathrm{DBA} \mathrm{A}^{-}$cells was normalized on the total number of $B R N 1^{+} / L T L^{-} / D B A^{-}$cells and expressed as percentage.

For early nephron analysis, E16.5 embryo sections were stained for pHH3 (cellular mitotic bodies), JAG1 and WT1. Transversal sections of renal vesicles, comma-shaped bodies and S-shaped bodies were counted by a single blinded observer using the Cell Counter plugin in the Fiji software. A section of early nephron structure was considered positive if containing one or more mitotic figures positive for $\mathrm{pHH} 3$. S-shaped bodies were divided in medial segment $\left(\mathrm{JAG}^{+}\right)$and distal segment $\left(\mathrm{JAG}^{-}{ }^{-}\right)$. The total number of positive early nephron sections was normalized on the total number of early nephron sections and expressed as percentage. 
Data were obtained from three biological replicates $(n=3)$ for each condition. So $11^{+/-}$and Sox $11^{+/+}$samples were considered as controls for this experiment. Statistical significance of the results was evaluated with Student's T-Test.

\section{Microarray study and data processing}

Total RNA was extracted, in 4 independent replicates, from dissected caudal area of urogenital ridges of Sox11 knockout and wildtype E10.75 embryos using the RNeasy MicroKit (Qiagen) followed by column DNase digestion to remove any contaminating genomic DNA. RNA preparations from the 2 different conditions were processed and hybridized on the Mouse Gene Array (Affymetrix). Arrays have been quantile-normalize with respect to the probe GC content using the RMA algorithm. Not or low expressed transcripts have been removed by a maximum expression cutoff $<50$. The data filtering in 206768 of 234872 probe sets and 27478 meta-probe sets defined in the full dataset. Differential expression of summarized gene level expression was calculated using the f-test statistic followed by a FDR multiple testing correction. Microarray data have been deposited in GEO under accession number GSE105426.

\section{Inclusion of CAKUT patients}

Participants included 560 patients for DNA analysis derived from 3 cohorts:

- 461 patients derived from the Dutch AGORA (Aetiologic research into Genetic and Occupational/environmental Risk factors for Anomalies in children) data- and biobank project, which comprises DNA as well as clinical and questionnaire data on lifestyle and environmental factors from patients diagnosed with congenital malformations or childhood cancers and their parents ${ }^{46}$. Patients were diagnosed with CAKUT at the Radboud university medical center, Amalia Children's Hospital, Nijmegen, The Netherlands.

- 83 patients derived from a duplex collecting system/vesico-ureteral reflux patient cohort that was described previously ${ }^{47}$.

- 16 children with CAKUT selected for mutational analysis in a multicenter approach. The inclusion criteria comprised renal hypodysplasia (RHD), double kidneys and/or anomalies of the ureter with RHD defined by the presence of small kidneys (<3rd percentile) and/or maldeveloped renal tissue on renal ultrasound. Sonographic criteria of maldeveloped renal tissue included lack of corticomedullary differentiation and optional the proof of renal cysts. Clinical information from the family members was collected wherever possible.

The study was approved by the ethical committees in all participating centers and informed assent and/or consent for genetic screening was obtained from patients and/or parents as appropriate. Peripheral blood samples were obtained and DNA was isolated from lymphocytes, using standard procedures. The patients and their diagnoses are summarized in Table S1.

\section{Mutation analysis of the human SOX11 gene in CAKUT patients}

The coding region and the intron-exon boundaries of the human SOX11 gene (NM_003108.3) were analyzed by Sanger sequencing. Primers applied and PCR settings are available upon request. In-house and the online available databases dbSNP, ensembl genome browser, 1000 genomes project and ExAC Browser were used to determine whether SOX11 variants were detected previously. Evaluation of a functional effect of the variants was assessed using PolyPhen-2 (http://genetics.bwh.harvard.edu/pph2/), SIFT (http://sift.jcvi.org/) and mutation taster (http://www.mutationtaster.org). 
Additional methods are available in supplementary material.

\section{Acknowledgements}

We would like to thank the team of the animal facility for their dedication. We are grateful to the patients, parents and healthcare providers for participating in the collection of patient data. We are indebted to F. Costantini (New York) and S. Cereghini (Paris) for the Gdnf and Papss2 ISH probes and Valerie Vidal for help with ISH experiments. This work was supported by grants from ANR (ANR-09-GENO-027-01 \& ANR-11-LABX-002801), ARC (SL22020605297), la Fondation de la Recherche Medicale (FRM, ING20160435020) and the EC (EURenOmics Grant agreement 305608; RenalTract). KR and AMvE were funded by the Dutch Kidney Foundation (KSTP.10.004 and C02.2009).

\section{Supplementary Material}

Supplementary information is available at KI Report's website.

\section{Supplementary file (pdf file) comprising:}

Figure S1: SOX11 expression during kidney development.

Figure S2: Genital tract abnormalities are associated with duplex kidneys in Sox11 knock-out mice.

Figure S3: Ex-vivo supernumerary bud formation in Sox11 knock-out embryos.

Figure S4: Rostral extension of the Gdnf expression domain in Sox11 mutants.

Figure S5: Expression of genes known to be involved in ureteric bud outgrowth is not affected by the absence of Sox11.

Figure S6: Nephron patterning genes are expressed in Sox11 mutants.

Figure S7: Analysis of proliferation and the $\mathrm{Wnt} / \beta$-catenin pathway.

Table S1: Number of patients analysed and phenotypic classification

Table S2: List of antibodies and primers used in this study.

Supplementary methods

Supplementary references

Supplementary data 1 (Excel file): Differentially expressed genes in Sox11 ko animals at E10.5

Supplementary data 2 (Excel file): Functional annotation chart

Supplementary data 3 (Excel file): RegRNA analysis

\section{References}

1. Schedl A. Renal abnormalities and their developmental origin. Nat Rev Genet. 2007;8(10):791-802.

2. Nicolaou N, Renkema KY, Bongers EM, Giles RH, Knoers NV. Genetic, environmental, and epigenetic factors involved in CAKUT. Nat Rev Nephrol. 2015;11(12):720-731.

3. Costantini F, Kopan R. Patterning a complex organ: branching morphogenesis and nephron segmentation in kidney development. Dev Cell. 2010;18(5):698-712.

4. Lu BC, Cebrian C, Chi X, et al. Etv4 and Etv5 are required downstream of GDNF and Ret for kidney branching morphogenesis. Nat Genet. 2009;41(12):1295-1302.

5. Davis TK, Hoshi M, Jain S. To bud or not to bud: the RET perspective in CAKUT. Pediatr Nephrol. 2014;29(4):597-608. 
6. Grieshammer U, Le M, Plump AS, Wang F, Tessier-Lavigne M, Martin GR. SLIT2-mediated ROBO2 signaling restricts kidney induction to a single site. Dev Cell. 2004;6(5):709-717.

7. Kume T, Deng K, Hogan BL. Murine forkhead/winged helix genes Foxc1 (Mf1) and Foxc2 (Mfh1) are required for the early organogenesis of the kidney and urinary tract. Development. 2000;127(7):1387-1395.

8. Kopan R, Chen S, Little M. Nephron progenitor cells: shifting the balance of self-renewal and differentiation. Current topics in developmental biology. 2014;107:293-331.

9. Lefebvre V, Dumitriu B, Penzo-Mendez A, Han Y, Pallavi B. Control of cell fate and differentiation by Sry-related high-mobility-group box (Sox) transcription factors. Int J Biochem Cell Biol. 2007;39(12):2195-2214.

10. Koopman P, Schepers G, Brenner S, Venkatesh B. Origin and diversity of the SOX transcription factor gene family: genome-wide analysis in Fugu rubripes. Gene. 2004;328:177-186.

11. Reginensi A, Clarkson M, Neirijnck Y, et al. SOX9 controls epithelial branching by activating RET effector genes during kidney development. Hum Mol Genet. 2011;20(6):1143-1153.

12. Kumar S, Liu J, Pang P, et al. Sox9 Activation Highlights a Cellular Pathway of Renal Repair in the Acutely Injured Mammalian Kidney. Cell reports. 2015;12(8):1325-1338.

13. Huang J, Arsenault M, Kann M, et al. The transcription factor Sry-related HMG box-4 (SOX4) is required for normal renal development in vivo. Dev Dyn. 2013;242(6):790-799.

14. Sock E, Rettig SD, Enderich J, BosI MR, Tamm ER, Wegner M. Gene targeting reveals a widespread role for the high-mobility-group transcription factor Sox11 in tissue remodeling. Mol Cell Biol. 2004;24(15):6635-6644.

15. Wurm A, Sock E, Fuchshofer R, Wegner M, Tamm ER. Anterior segment dysgenesis in the eyes of mice deficient for the high-mobility-group transcription factor Sox11. Experimental eye research. 2008;86(6):895-907.

16. Hoser M, Potzner MR, Koch JM, BosI MR, Wegner M, Sock E. Sox12 deletion in the mouse reveals nonreciprocal redundancy with the related Sox 4 and Sox11 transcription factors. Mol Cell Biol. 2008;28(15):4675-4687.

17. Grote D, Boualia SK, Souabni A, et al. Gata3 acts downstream of beta-catenin signaling to prevent ectopic metanephric kidney induction. PLoS Genet. 2008;4(12):e1000316.

18. Basson MA, Akbulut $\mathrm{S}$, Watson-Johnson J, et al. Sprouty1 is a critical regulator of GDNF/RETmediated kidney induction. Dev Cell. 2005;8(2):229-239.

19. Miyazaki Y, Oshima K, Fogo A, Hogan BL, Ichikawa I. Bone morphogenetic protein 4 regulates the budding site and elongation of the mouse ureter. J Clin Invest. 2000;105(7):863-873.

20. Huang da W, Sherman BT, Lempicki RA. Systematic and integrative analysis of large gene lists using DAVID bioinformatics resources. Nat Protoc. 2009;4(1):44-57.

21. Hirayama T, Yagi T. Clustered protocadherins and neuronal diversity. Progress in molecular biology and translational science. 2013;116:145-167.

22. Yokota S, Hirayama T, Hirano K, et al. Identification of the cluster control region for the protocadherin-beta genes located beyond the protocadherin-gamma cluster. J Biol Chem. 2011;286(36):31885-31895.

23. Yu J, Carroll TJ, Rajagopal J, Kobayashi A, Ren Q, McMahon AP. A Wnt7b-dependent pathway regulates the orientation of epithelial cell division and establishes the cortico-medullary axis of the mammalian kidney. Development. 2009;136(1):161-171.

24. Genomes Project C, Abecasis GR, Auton A, et al. An integrated map of genetic variation from 1,092 human genomes. Nature. 2012;491(7422):56-65.

25. Sherry ST, Ward MH, Kholodov M, et al. dbSNP: the NCBI database of genetic variation. Nucleic Acids Res. 2001;29(1):308-311.

26. Lek M, Karczewski K, Minikel E, et al. Analysis of protein-coding genetic variation in 60,706 humans. bioRxiv. 2015.

27. Chang TH, Huang HY, Hsu JB, Weng SL, Horng JT, Huang HD. An enhanced computational platform for investigating the roles of regulatory RNA and for identifying functional RNA motifs. BMC bioinformatics. 2013;14 Suppl 2:S4.

28. Kan A, Ikeda T, Fukai A, et al. SOX11 contributes to the regulation of GDF5 in joint maintenance. BMC developmental biology. 2013;13:4.

29. Nishita M, Qiao S, Miyamoto M, et al. Role of Wnt5a-Ror2 signaling in morphogenesis of the metanephric mesenchyme during ureteric budding. Mol Cell Biol. 2014;34(16):3096-3105.

30. Yun K, Ajima R, Sharma N, et al. Non-canonical Wnt5a/Ror2 signaling regulates kidney morphogenesis by controlling intermediate mesoderm extension. Hum Mol Genet. 2014;23(25):6807-6814.

31. Takamatsu H, Takegahara N, Nakagawa Y, et al. Semaphorins guide the entry of dendritic cells into the lymphatics by activating myosin II. Nature immunology. 2010;11(7):594-600. 
32. Yamashita N, Mosinger B, Roy A, et al. CRMP5 (collapsin response mediator protein 5) regulates dendritic development and synaptic plasticity in the cerebellar Purkinje cells. $J$ Neurosci. 2011;31(5):1773-1779.

33. Tufro A, Teichman J, Woda C, Villegas G. Semaphorin3a inhibits ureteric bud branching morphogenesis. Mech Dev. 2008;125(5-6):558-568.

34. Xu L, Huang S, Hou Y, et al. Sox11-modified mesenchymal stem cells (MSCs) accelerate bone fracture healing: Sox11 regulates differentiation and migration of MSCs. FASEB journal : official publication of the Federation of American Societies for Experimental Biology. 2015;29(4):1143-1152.

35. Chi X, Michos O, Shakya R, et al. Ret-dependent cell rearrangements in the Wolffian duct epithelium initiate ureteric bud morphogenesis. Dev Cell. 2009;17(2):199-209.

36. Kuure $S$, Cebrian $C$, Machingo $Q$, et al. Actin depolymerizing factors cofilin1 and destrin are required for ureteric bud branching morphogenesis. PLoS Genet. 2010;6(10):e1001176.

37. Murugan S, Shan J, Kuhl SJ, et al. WT1 and Sox11 regulate synergistically the promoter of the Wnt4 gene that encodes a critical signal for nephrogenesis. Exp Cell Res. 2012;318(10):1134-1145.

38. Lindstrom NO, Lawrence ML, Burn SF, et al. Integrated beta-catenin, BMP, PTEN, and Notch signalling patterns the nephron. eLife. 2014;3:e04000.

39. Desgrange A, Cereghini S. Nephron Patterning: Lessons from Xenopus, Zebrafish, and Mouse Studies. Cells. 2015;4(3):483-499.

40. Zimmermann S, Steding G, Emmen JM, et al. Targeted disruption of the InsI3 gene causes bilateral cryptorchidism. Mol Endocrinol. 1999;13(5):681-691.

41. Hutson JM, Hasthorpe S, Heyns CF. Anatomical and functional aspects of testicular descent and cryptorchidism. Endocr Rev. 1997;18(2):259-280.

42. Nef S, Parada LF. Cryptorchidism in mice mutant for InsI3. Nat Genet. 1999;22(3):295-299.

43. Jain S, Encinas M, Johnson EM, Jr., Milbrandt J. Critical and distinct roles for key RET tyrosine docking sites in renal development. Genes Dev. 2006;20(3):321-333.

44. Nicolaou N, Pulit SL, Nijman IJ, et al. Prioritization and burden analysis of rare variants in 208 candidate genes suggest they do not play a major role in CAKUT. Kidney Int. 2015.

45. Pillai-Kastoori L, Wen W, Wilson SG, et al. Sox11 is required to maintain proper levels of Hedgehog signaling during vertebrate ocular morphogenesis. PLoS Genet. 2014;10(7):e1004491.

46. van Rooij IA, van der Zanden LF, Bongers EM, et al. AGORA, a data- and biobank for birth defects and childhood cancer. Birth Defects Res A Clin Mol Teratol. 2016.

47. van Eerde AM, Duran K, van Riel E, et al. Genes in the ureteric budding pathway: association study on vesico-ureteral reflux patients. PLoS One. 2012;7(4):e31327.

\section{Figure Legends}

\section{Figure 1. Dynamic expression of Sox11 during kidney development.}

(A) Immunofluorescence analysis of wildtype embryos shows SOX11 expression in the metanephric mesenchyme (SIX2+) and Wolffian duct/ureteric bud (CYTOKERATIN+) at E11.0 (left panel). At E16.5, SOX11 expression is maintained at low levels in the Wolffian duct derivatives (ureteric tips and collecting ducts) and at high levels in the metanephric mesenchyme derivatives (cap mesenchyme and nascent nephrons) (middle and right panels). (B) High power view showing that SOX11 is absent from FOXD1-positive stromal cells. (C) High magnification of a renal vesicle and S-shaped body of a wildtype E16.5 embryo showing SOX11 expression in the proximal (WT1+), middle (JAG1+) and distal (PAX2+ JAG1- WT1-) segments. Note the higher SOX11 expression in the distal RV and middle SSB segments. (D) Immunostaining of SOX11 at different stages of kidney development (E12.5, E18.5, P1 and adult). Simultaneous staining with WT1 and Laminin has been used to visualize the different renal structures. (E) SOX11 is expressed in the urethra of E12.5 embryos. WD : wolffian duct, UB : ureteric bud, MM : metanephric mesenchyme, UT : ureteric tip, CD : collecting duct, $\mathrm{CM}$ : cap mesenchyme, NN : nascent nephron, EN : elongating nephron, RV : renal vesicle,

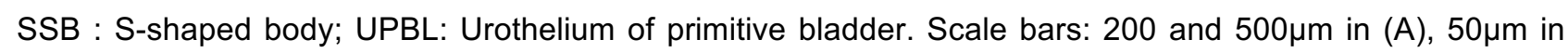
$(B, C), 100 \mu m$ in (D). 


\section{Figure 2. Kidney and ureter abnormalities in Sox11 knockout mice.}

Urinary tract of E18.5 mice were processed as whole-mount (A-C) or with PAS staining on tissue sections (DH). Control Sox $11^{+/+}$embryos (A,D) showing normal kidneys (k), adrenal glands (a), ureters (black arrowhead) and bladder (b). Sox $11^{+/-}(\mathrm{B}, \mathrm{E}, \mathrm{H})$ and Sox $11^{-/-}(\mathrm{C}, \mathrm{F})$ embryos showing duplex kidneys, hydronephrosis $\left({ }^{*}\right)$ and hydroureter (red arrowheads). (I) Frequency of CAKUT phenotype in So $111^{+/+}$, Sox $11^{+/-}$and Sox $11^{-/}$embryos at PO. Scale bar: $1 \mathrm{~mm}$

Figure 3. Loss of Sox11 results in supernumerary ureteric buds and rostral extension of the Gdnf expression domain.

(A,B) Dissected urogenital tracts of E11.5 mutant embryos were processed for wholemount ISH using a c-Ret probe. A single ureteric bud (black arrowhead) has emerged and branched in Sox $11^{+/+}$embryo, whereas two ureteric buds (black and red arrowheads) had formed in the absence of Sox11. (C-F) Wholemount ISH on urogenital tracts of E10.75 embryos using Gdnf and Six2 probes shows a rostral extension of the Gdnf and Six 2 expression domain in Sox $11^{-/}$(black arrows, right panel) compared to Sox $11^{+/+}$(left panel). Scale bar: $100 \mu \mathrm{m}$.

Figure 4. Microarray and ChIP analysis identifies the protocadherin $\beta$ cluster as a direct target of SOX11 (A) Relative fold change expression (Sox $11^{-/} /$Sox $11^{+/+}$) of protocadherin genes obtained by microarray (ns non-significant, $\left.{ }^{*} p<0.5,{ }^{* *} p<0.01,{ }^{* * *} p<0.001\right)$. (B) Relative fold change expression $\left(\right.$ So $11^{-/} /$Sox $\left.11^{+/+}\right)$of chromosome 18 genes obtained by microarray $(p<0.05)$, plotted against their chromosomal location (C) Schematic representation of the protocadherin- $\alpha$ (green), $-\beta$ (red) and $-\gamma$ (blue) locus. The Pcdh $\beta$-cluster control region (CCR) is represented as a red box, containing 4 DNasel hypersensitivity sites (HS16, 17-17', 18 and 19-20). Red arrows represent the primers used for ChIP analysis. ChIP-qPCR analysis $(n=2)$ reveals an 8 fold enrichment of HS19-20 in SOX11-immunoprecipitated chromatin versus IGG-immunoprecipitated chromatin. No difference was seen on a control locus.

Figure 5. Loss of Sox11 causes changes in renal architecture.

(A-B) PAS staining of P0 kidneys from wild-type and Sox $11^{-\%}$ animals. Closer views of the medullary zone $\left(\mathbf{A}^{\prime}, \mathbf{B}^{\prime}\right)$ shows a reduction of epithelial components and an increase of stromal tissue in Sox11 mutant embryos compared to controls. Black arrows point to collection duct and red arrowheads to stromal cells. (CJ) ISH analysis of nephron segments in E18.5 Sox $11^{+/+}$(left panel) and Sox $11^{-/}$(right panel) embryos. S/c5a2, S/c5a1, Nkcc2 and $N c c$ riboprobes were used to visualize segments $S 1 / S 2$ of proximal tubules, segments $S 3$ of proximal tubules, Henle's loops and distal tubules, respectively. Scale bars: $1 \mathrm{~mm}$ in $(A, B), 500 \mu m$ in (C-J).

Figure 6. Nephron segment defects in Sox11 mutant mice.

Immunofluorescence analysis of nephron segments in E17.5 Sox $11^{+/+}$(left panel) and Sox $11^{-/}$(right panel) embryos. Podocin/NPHS2 (A,B), Lotus Tetragonolobus Lectin/LTL (D,E), Tamm-Horsfall protein/THP (G,H) and $\mathrm{NaCl}$ cotransporter/NCC $(\mathrm{J}, \mathrm{K})$ were used to visualize glomeruli, proximal tubules, Henle's loops and distal tubules, respectively. Dotted lines in $\mathbf{D}$ and $\mathbf{E}$ highlight the renal cortex containing the $\mathrm{S} 1$ and $\mathrm{S} 2$ segment of proximal tubules. (C, F, I, L) Quantification of glomeruli and cells in proximal (LTL+), Henle's loop (THP+) and 
distal (NCC+) tubules in Sox $11^{+/+}$, Sox $11^{+/-}$and Sox $11^{-/}$E17.5 embryos. Cells number is presented as the average with SEM of data obtained from three embryos of each genotype $\left({ }^{*} p<0.05,{ }^{* *} p<0.01,{ }^{* * *} p<0.001\right)$. Scale bars: $200 \mu \mathrm{m}$.

Figure 7. Coding sequence variants of SOX11 found in CAKUT patients.

Linear representation of the human SOX11 protein showing the location of the variants identified in the CAKUT cohort. The coding sequence variations (black) and the corresponding amino-acid changes (red) are indicated. Functional domains previously reported are displayed in blue: High Mobility Group (HMG) DNA binding domain (HMG aa.47-122) and trans-activation domain (TA aa.408-441). Amino-acid positions are displayed in grey.

Table 1. Sox11 is required in the mesenchymal compartment to ensure proper kidney development. Frequency and detailed kidney phenotypes of Sox 11 knockout and Sox $11^{-/+}$mutant mice. Note that hydroureter and hydronephrosis defects were always found in association with duplex kidney.

\section{Table 2. Coding sequence variants of SOX11 found in CAKUT patients.}

SOX11 variants identified in CAKUT cohort, their associated phenotypes, frequency in our CAKUT cohort and the ExAC database, and in silico mutation prediction results. Patients' phenotypes that were also displayed by the Sox11 knockout are highlighted in bold. 
A

E11.0

E16.5
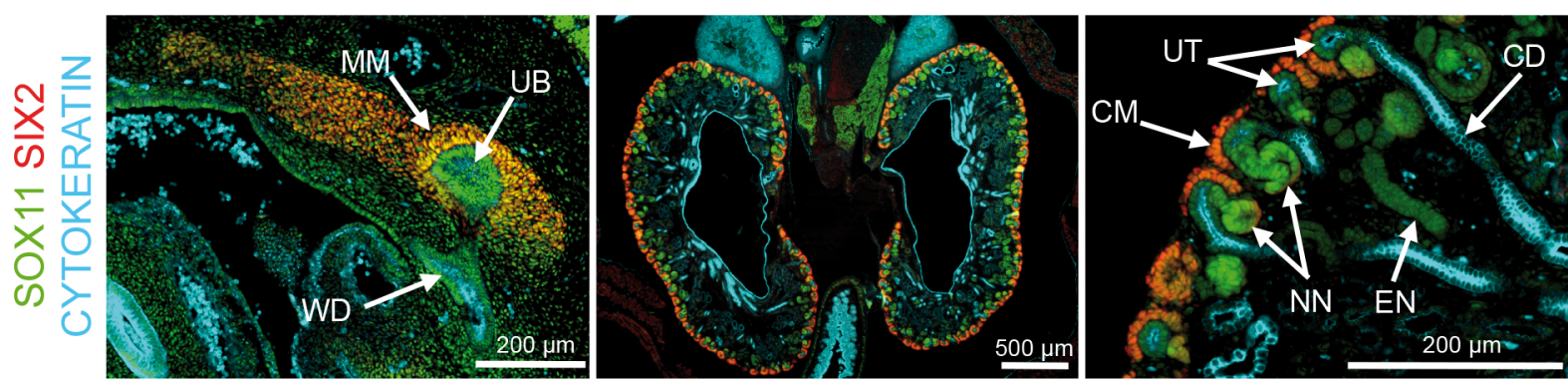

B

E14.5

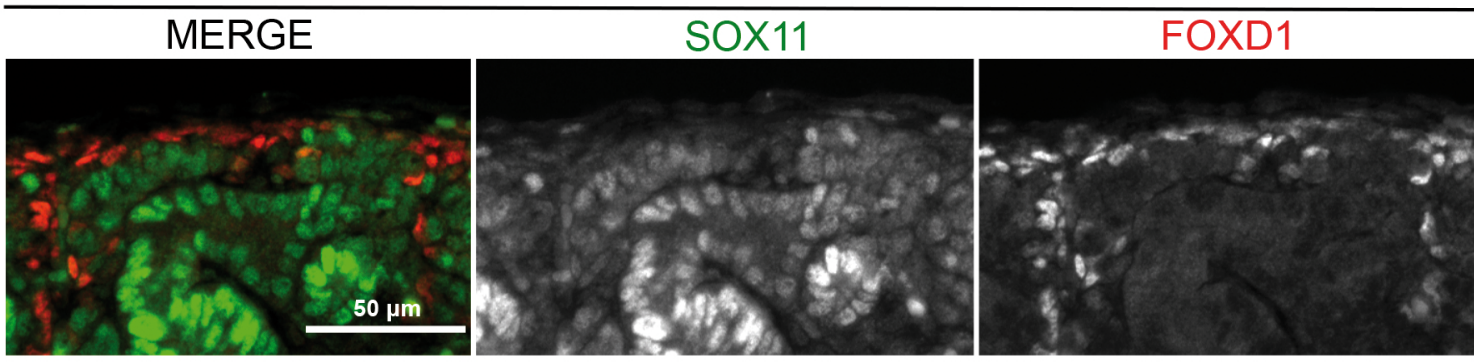

C

E16.5
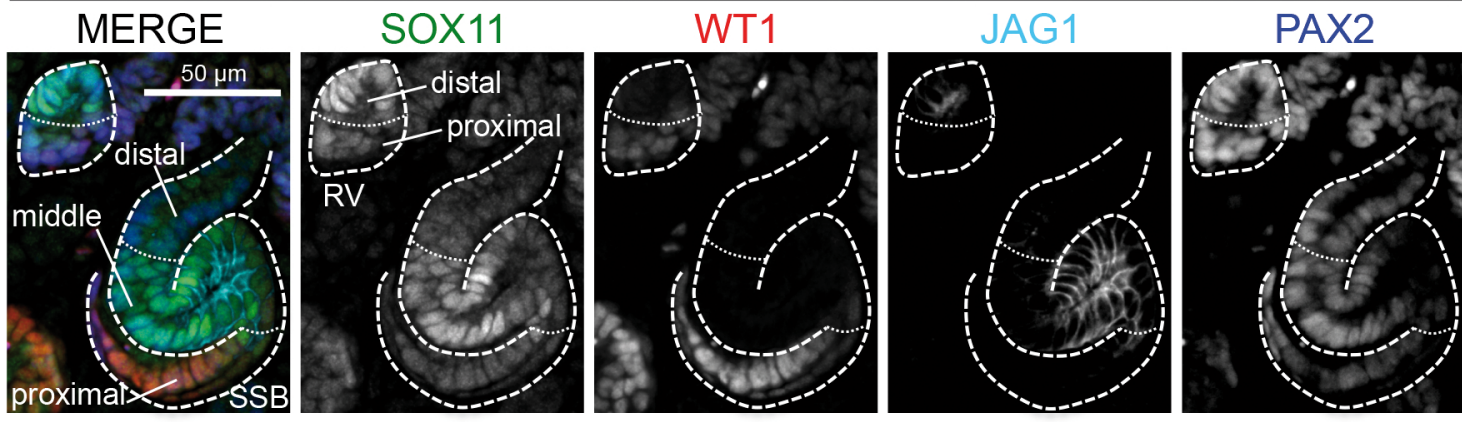

D
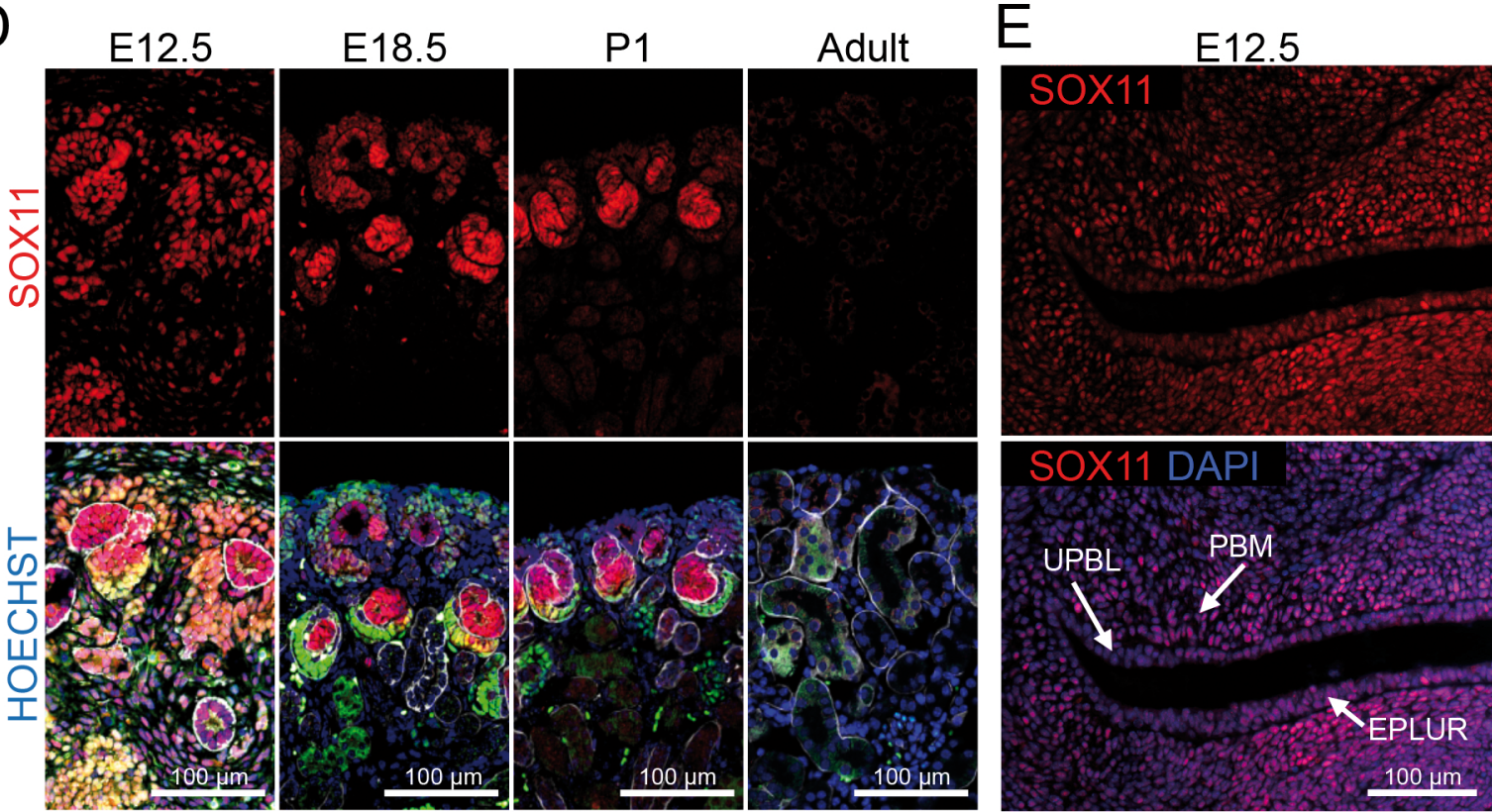


\section{Sox $11^{+/+}$}

A

100 um

E10.75

\section{Sox $11^{+/+} \quad$ Sox $11^{-/-}$}

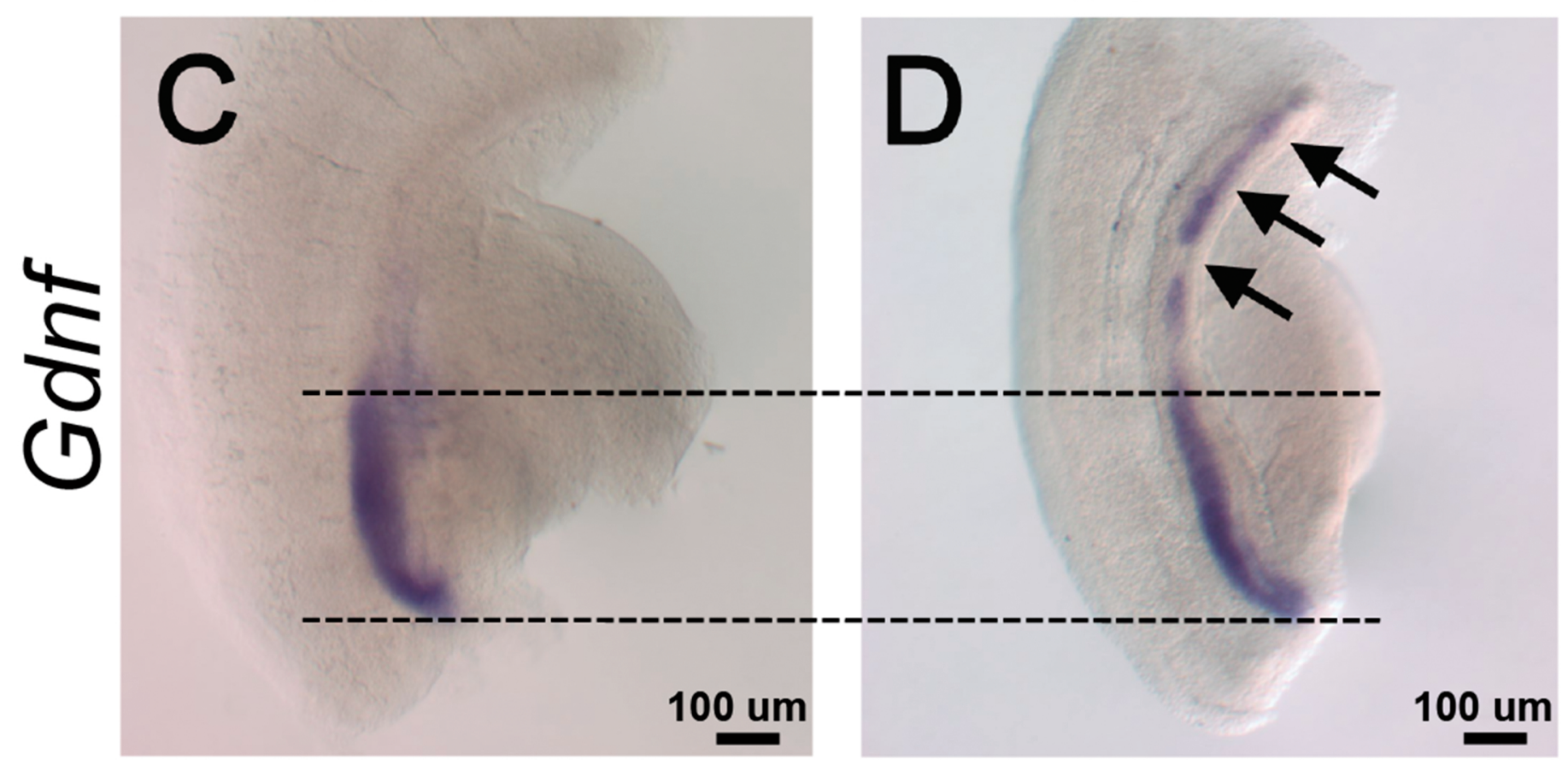

$\frac{x}{\omega}$

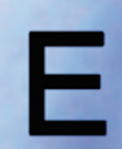




\section{Fold change Sox11// Sox11//+}

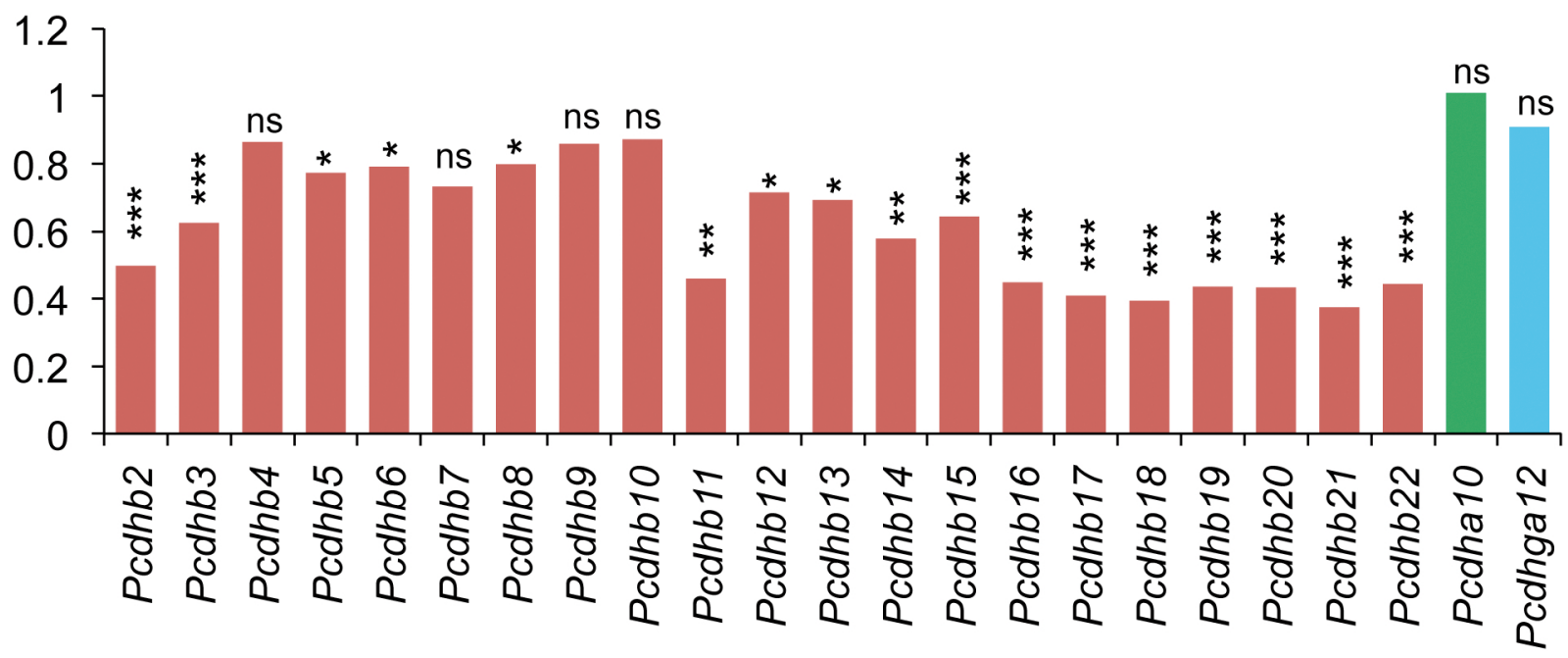

B

Fold change Sox11/ / Sox11 $1 /+$

plotted against chromosome 18 position

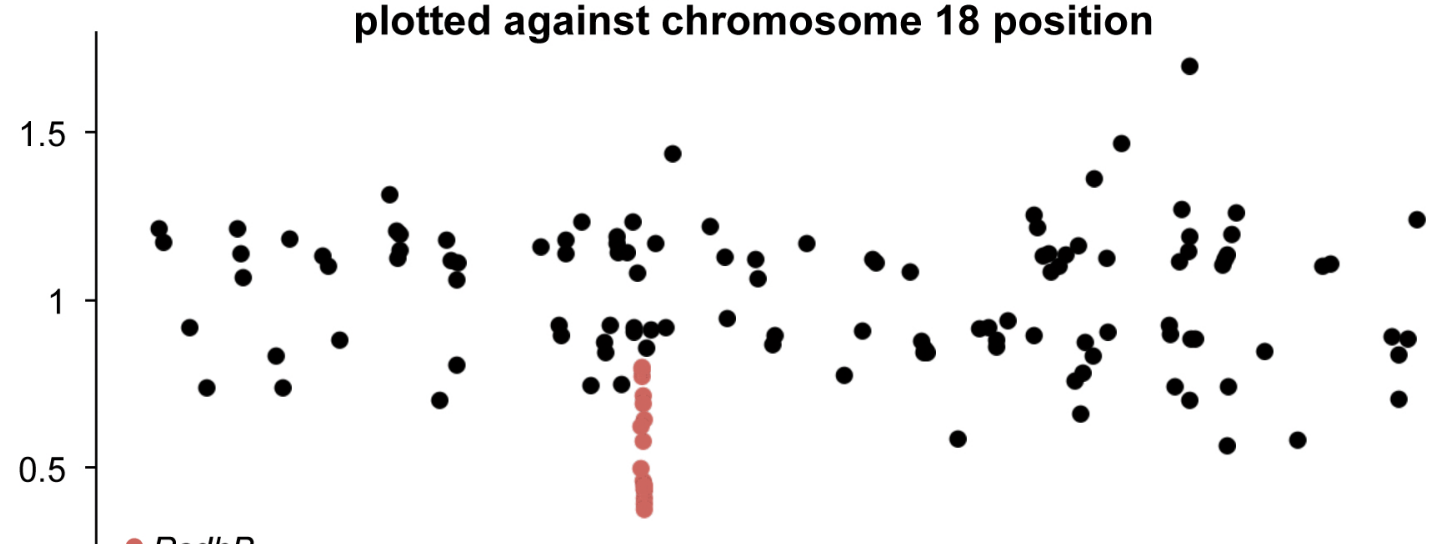

C

- other

$\begin{array}{rrrrrr}0 & & & & & \\ 0 & 20000000 & 40000000 & 60000000 & 80000000 & 100000000\end{array}$

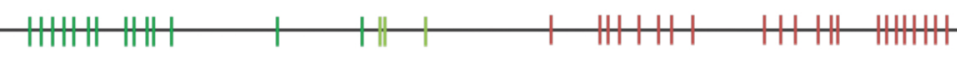

$P \operatorname{cdh} \beta$

Pcdhy $\frac{100 \mathrm{~kb}}{\mathrm{CCR}}$

Relative fold enrichment

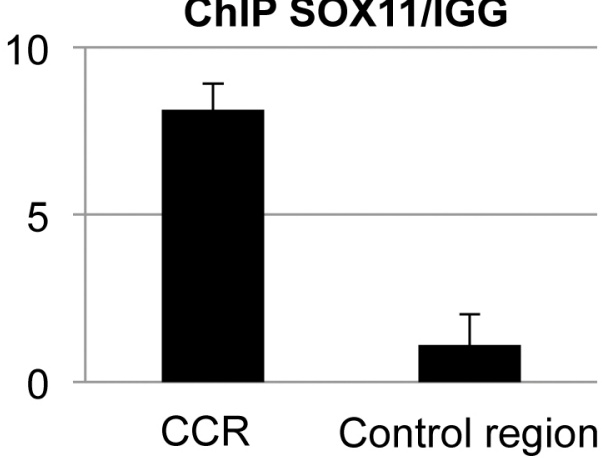

SIc25a2

Diap1:

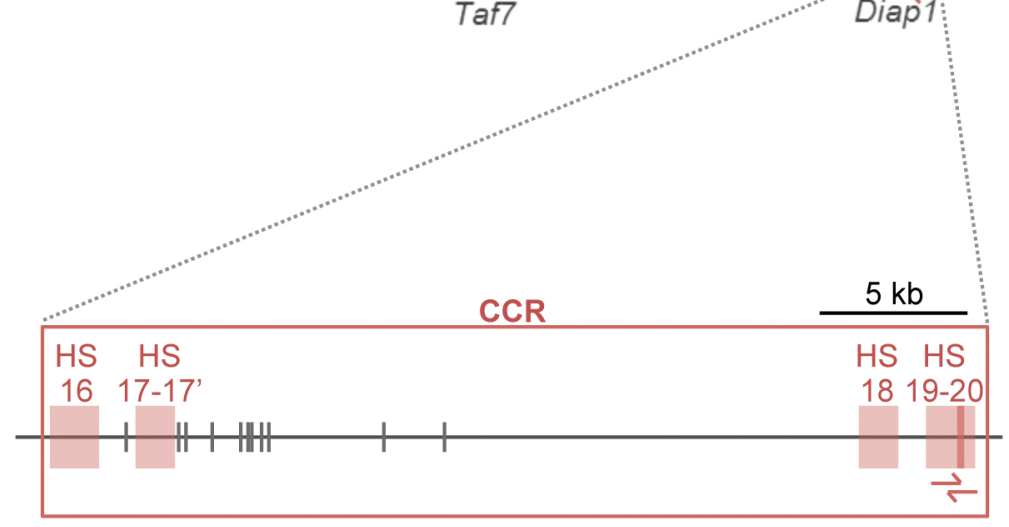



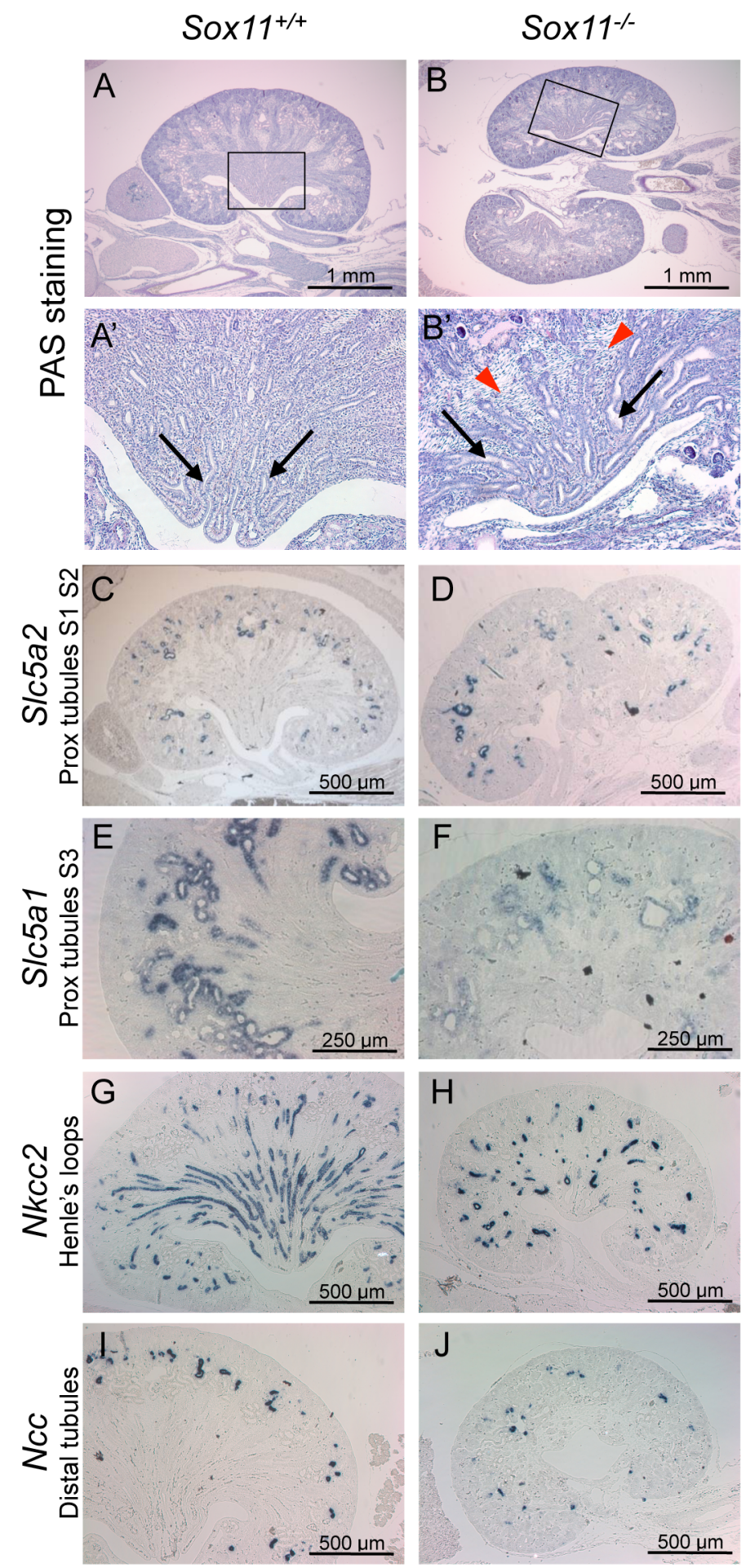


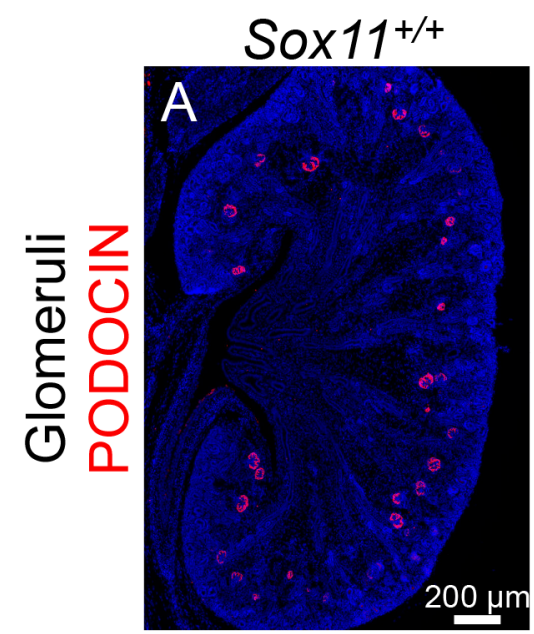

Sox11--
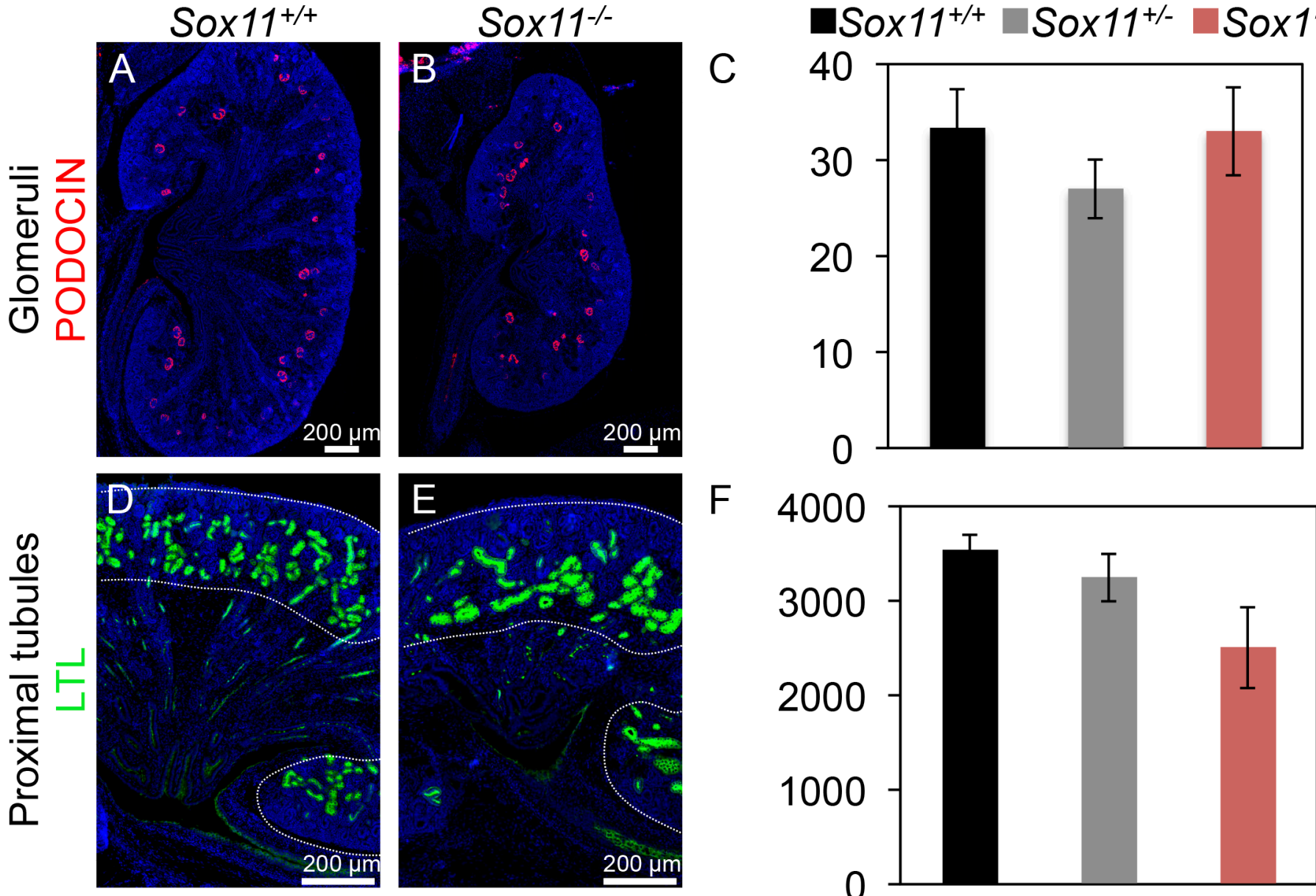

$\mathrm{F}$
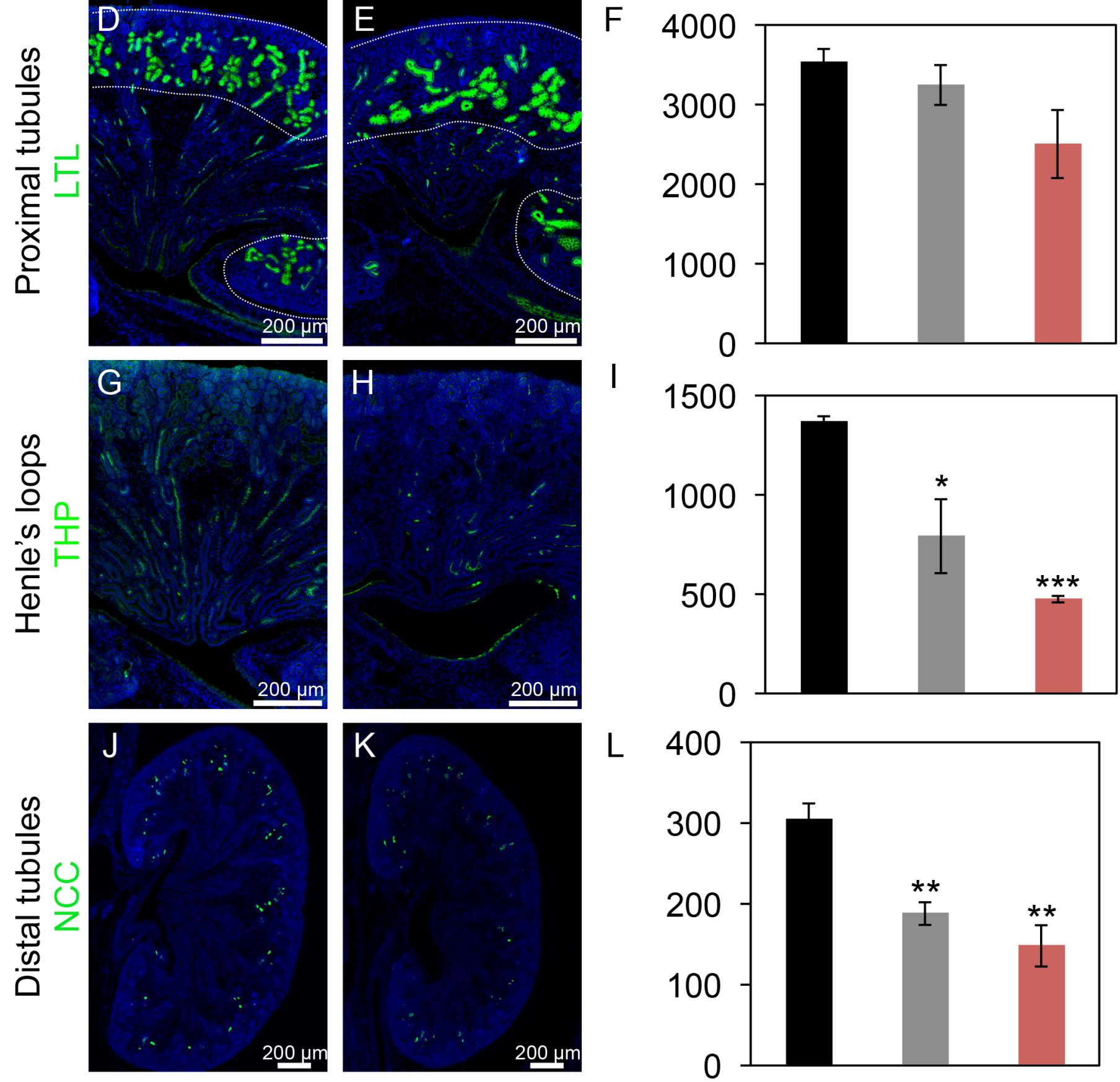


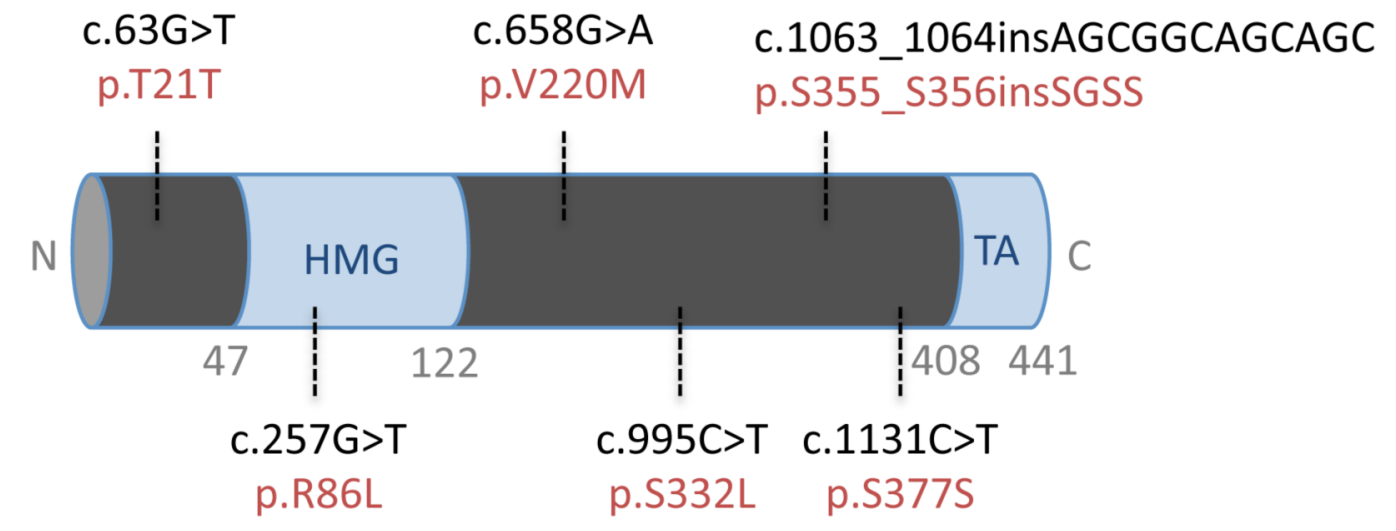


Table 1: Sox11 is required to ensure proper kidney development.

\begin{tabular}{|l|l|l|l|c|c|c|c|c|c|}
\hline \multirow{2}{*}{ Genotype } & $\mathbf{n}$ & \multirow{2}{*}{$\begin{array}{l}\text { Normal } \\
(\%)\end{array}$} & $\begin{array}{l}\text { CAKUT } \\
(\%)\end{array}$ & \multicolumn{2}{|c|}{ Duplex kidney } & \multirow{2}{*}{ Hydroureter } & Hydronephrosis & \multicolumn{2}{|c|}{ Hypoplasia } \\
\cline { 3 - 4 } & & Unilateral & Bilateral & & Unilateral & Bilateral \\
\hline So $11^{+/+}$ & 26 & $\begin{array}{l}26 \\
(100 \%)\end{array}$ & $0(0 \%)$ & & & & & & \\
\hline So $11^{+/}$ & 39 & $\begin{array}{l}37 \\
(94,9 \%)\end{array}$ & $\begin{array}{l}2 \\
(5,1 \%)\end{array}$ & 2 & & 2 & 2 & & \\
\hline So $\times 11^{-/}$ & 21 & $\begin{array}{l}7 \\
(33,3 \%)\end{array}$ & $\begin{array}{l}14 \\
(66,7 \%)\end{array}$ & 7 & 5 & 2 & 1 & 2 & 2 \\
\hline
\end{tabular}




\begin{tabular}{|c|c|c|c|c|c|c|c|c|c|c|c|c|}
\hline \multicolumn{2}{|c|}{ Patient } & 1 & \multicolumn{2}{|c|}{2} & 3 & \multicolumn{3}{|c|}{4} & \multicolumn{2}{|c|}{5} & \multicolumn{2}{|l|}{6} \\
\hline \multicolumn{2}{|c|}{ Gender } & Male & \multicolumn{2}{|c|}{ Male } & Female & \multicolumn{3}{|c|}{ Male } & \multicolumn{2}{|c|}{ Male } & \multicolumn{2}{|c|}{ Male } \\
\hline \multicolumn{2}{|c|}{ Country } & $\begin{array}{c}\text { The } \\
\text { Netherlands }\end{array}$ & \multicolumn{2}{|c|}{ The Netherlands } & The Netherlands & \multicolumn{3}{|c|}{ Germany } & \multicolumn{2}{|c|}{ Germany } & \multicolumn{2}{|c|}{ The Netherlands } \\
\hline \multicolumn{2}{|c|}{ Ethnicity } & Caucasian & \multicolumn{2}{|c|}{ Caucasian } & Caucasian & \multicolumn{3}{|c|}{ Caucasian } & \multicolumn{2}{|c|}{ Caucasian } & \multicolumn{2}{|c|}{ Caucasian } \\
\hline \multirow{5}{*}{\multicolumn{2}{|c|}{ Phenotype }} & \multirow{5}{*}{$\begin{array}{c}\text { Posterior } \\
\text { urethral } \\
\text { valves }\end{array}$} & \multirow{5}{*}{\multicolumn{2}{|c|}{ Multicystic kidney dysplasia (left) }} & \multirow{2}{*}{$\begin{array}{c}\text { Duplex } \\
\text { collecting } \\
\text { system (right) }\end{array}$} & \multicolumn{3}{|c|}{ Posterior urethral valves } & \multicolumn{2}{|c|}{ Posterior urethral valves } & \multirow{2}{*}{\multicolumn{2}{|c|}{$\begin{array}{c}\begin{array}{c}\text { Ureteropelvic junction } \\
\text { obstruction (left) }\end{array} \\
\begin{array}{c}\text { Maldescended testis } \\
\text { (right) }\end{array} \\
\end{array}$}} \\
\hline & & & & & & \multicolumn{3}{|c|}{ Multicystic kidney dysplasia (bilateral) } & \multirow{4}{*}{\multicolumn{2}{|c|}{ Kidney hypoplasia (bilateral) }} & & \\
\hline & & & & & $\begin{array}{c}\text { Ureteropelvic } \\
\text { junction } \\
\text { obstruction } \\
\text { (right) } \\
\end{array}$ & & atic fibrosi & & & & Urethral meat & 1 stenosis \\
\hline & & & & & \multirow{2}{*}{$\begin{array}{l}\text { Vesicoureteral } \\
\text { reflux (right) }\end{array}$} & & al degenrati & & & & Hearing & \\
\hline & & & & & & Skel & 1 abnormal & & & & Glaucoma ( & (lateral) \\
\hline $\begin{array}{r}\text { Position o } \\
\text { (GR }\end{array}$ & $\begin{array}{l}\text { aromosome } 2 \\
\text { 38.p2) }\end{array}$ & 5692784 & 569 & & 5693716 & & 5693784 & & 5693784 & 5693379 & 56938 & \\
\hline $\begin{array}{r}\text { Coding s } \\
\text { (NM }\end{array}$ & $\begin{array}{l}\text { ence change } \\
\text { 3108.3) }\end{array}$ & c. $63 \mathrm{G}>\mathrm{T}$ & c. 25 & $\mathrm{G}>\mathrm{T}$ & c. $995 \mathrm{C}>\mathrm{T}$ & c.1063in & GCGGCAC & & $\begin{array}{c}\text { c.1063insAGCGG } \\
\text { CAGCAGC }\end{array}$ & c. $658 \mathrm{G}>\mathrm{A}$ & c. 1131 & \\
\hline Type & nutation & Silent & Mis & & Missense & & Insertion & & Insertion & Missense & Siler & \\
\hline $\begin{array}{r}\operatorname{Amino} \\
(\mathbf{N P}\end{array}$ & id change & p.T21T & & & p.S332L & & 55insSGSS & & p.355insSGSS & p.V220M & p.S37 & \\
\hline Variar & bSNP ID & rs 139885563 & rs 202 & 11730 & novel & & novel & & novel & rs758958162 & rs762687158 (n & t validated) \\
\hline Allele & $\begin{array}{c}\text { ExAC (non- } \\
\text { Finnish } \\
\text { Europeans) }\end{array}$ & 0.001 & & & - & & - & & - & 0.0003 & 0.000 & \\
\hline trequency & $\begin{array}{c}\text { Our CAKUT } \\
\text { cohort }\end{array}$ & 0.0009 & & & 0.0009 & & 0.002 & & 0.002 & 0.0009 & 0.000 & \\
\hline & prediction & - & probably & lamaging & $\begin{array}{c}\text { probably } \\
\text { damaging }\end{array}$ & & - & & - & $\begin{array}{c}\text { probably } \\
\text { damaging }\end{array}$ & - & \\
\hline PolyPhen-2 & score & - & & & 0.991 & & - & & - & 0.996 & - & \\
\hline & sensitivity & - & & & 0.71 & & - & & - & 0.55 & - & \\
\hline & specificity & - & & & 0.97 & & - & & - & 0.98 & - & \\
\hline Mutation & prediction & - & disease & causing & disease causing & & - & & - & disease causing & - & \\
\hline Taster & prob & - & & & 0.999 & & - & & - & 0.996 & - & \\
\hline SIFT & prediction & - & & & tolerated & & - & & - & tolerated & - & \\
\hline DIT & score & - & & & 0.14 & & - & & - & 0.11 & - & \\
\hline $\begin{array}{c}\text { RegRna } \\
\text { prediction }\end{array}$ & Motif type & $\begin{array}{c}\text { intron } \\
\text { splicing } \\
\text { enhancer }\end{array}$ & $\begin{array}{c}\text { functional RNA } \\
\text { sequences }\end{array}$ & $\begin{array}{c}\text { functional RNA } \\
\text { sequences }\end{array}$ & $\begin{array}{l}\text { Transcriptional } \\
\text { regulatory motif }\end{array}$ & $\begin{array}{l}\text { Transcriptional } \\
\text { regulatory motif }\end{array}$ & $\begin{array}{l}\text { Human } \\
\text { splicing } \\
\text { sites }\end{array}$ & $\begin{array}{l}\text { Human } \\
\text { splicing } \\
\text { sites }\end{array}$ & $\begin{array}{l}\text { Transcriptional } \\
\text { regulatory motif }\end{array}$ & $\begin{array}{l}\text { intron splicing } \\
\text { enhancer }\end{array}$ & $\begin{array}{c}\text { Human } \\
\text { splicing sites }\end{array}$ & $\begin{array}{c}\text { intron } \\
\text { splicing } \\
\text { enhancer } \\
\text { (ISE) }\end{array}$ \\
\hline
\end{tabular}




\begin{tabular}{|c|c|c|c|c|c|c|c|c|c|c|c|}
\hline Motif name & gh-1 intron 3 & $\begin{array}{l}\text { FR084090/Grou } \\
\text { p_I_intron }\end{array}$ & $\begin{array}{l}\text { FR012169/Putat } \\
\text { ive_conserved_- } \\
\text { noncoding_regi } \\
\text { on_(EvoFold) }\end{array}$ & $\mathrm{HIC} 1$ & BEN & donor & acceptor & BEN & $\begin{array}{l}\text { amyloid precursor } \\
\text { protein, exon } 8\end{array}$ & donor & $\begin{array}{c}\text { ighg2 } \\
\text { cgamma2 } \\
\text { (immunog } \\
\text { lobulin } \\
\text { heavy } \\
\text { chain } \\
\text { subclass } \\
\text { g2- } \\
\text { cgamma2 } \\
\text { gene) - } \\
\text { intron 1 }\end{array}$ \\
\hline $\begin{array}{c}\text { Change in } \\
\text { variant versus } \\
\text { wildtype }\end{array}$ & suppressed & suppressed & additional & additional & additional & suppressed & additional & additional & additional & additional & additional \\
\hline
\end{tabular}

Table 2. Coding sequence variants of SOX11 found in CAKUT patients.

SOX11 variants identified in CAKUT cohort, their associated phenotypes, frequency in our CAKUT cohort and the EXAC database, and in silico mutation prediction results. Patients' phenotypes that were also displayed by the Sox11 knockout are highlighted in bold. 


\section{SUPPLEMENTARY INFORMATION INVENTORY}

Figure S1: SOX11 expression during kidney development.

Figure S2: Genital tract abnormalities are associated with duplex kidneys in Sox11 knock-out mice.

Figure S3: Ex-vivo supernumerary bud formation in Sox11 knock-out embryos.

Figure S4: Rostral extension of the Gdnf expression domain in Sox11 mutants.

Figure S5: Expression of genes known to be involved in ureteric bud outgrowth is not affected by the absence of Sox11.

Figure S6: Nephron patterning genes are expressed in Sox11 mutants.

Figure S7: Analysis of proliferation and the Wnt/ $\beta$-catenin pathway.

Table S1: Number of patients analysed and phenotypic classification

Table S2: List of antibodies and primers used in this study.

\section{Supplementary methods}

Supplementary references 


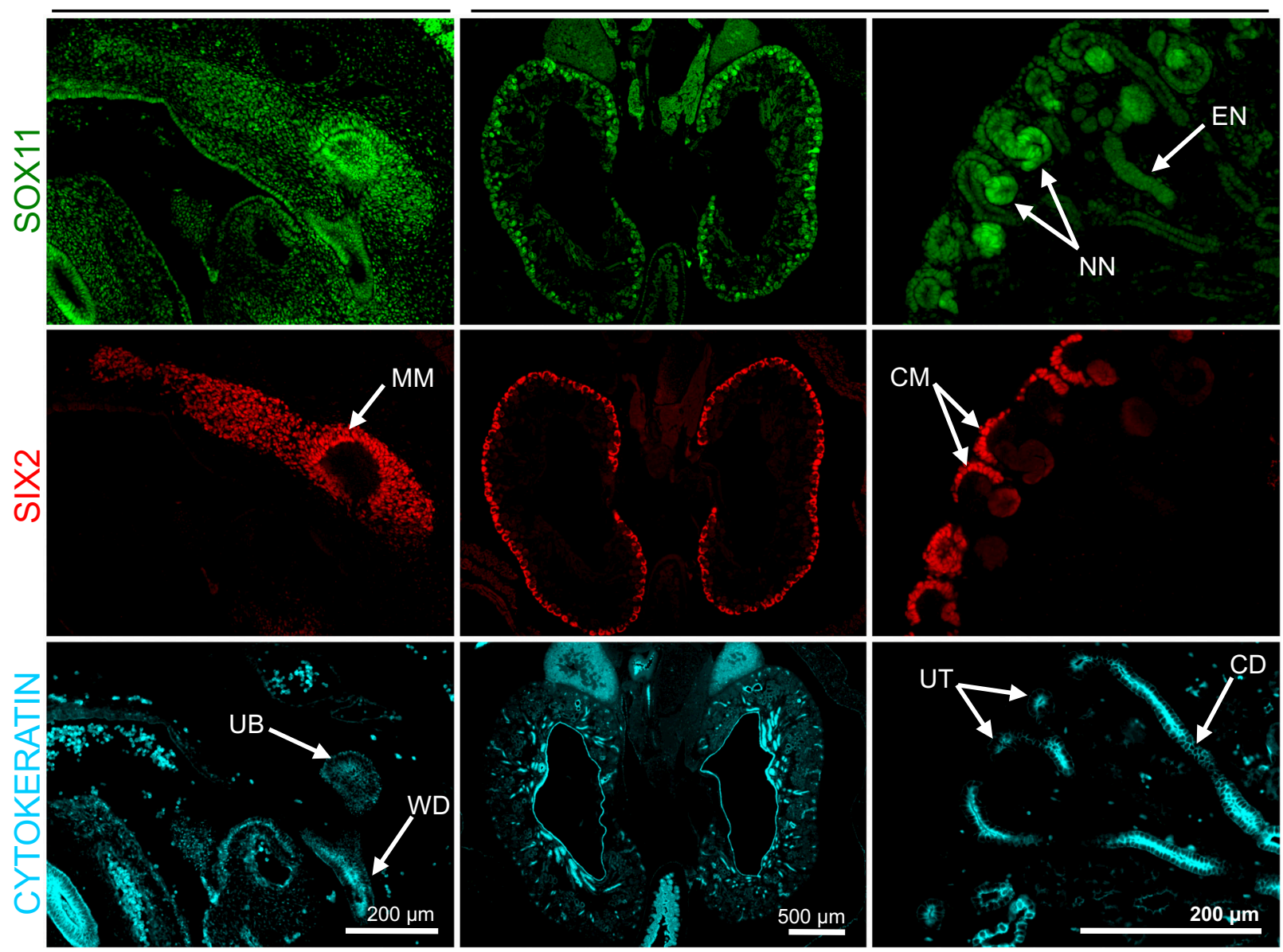

$\mathrm{B}$

E10.75

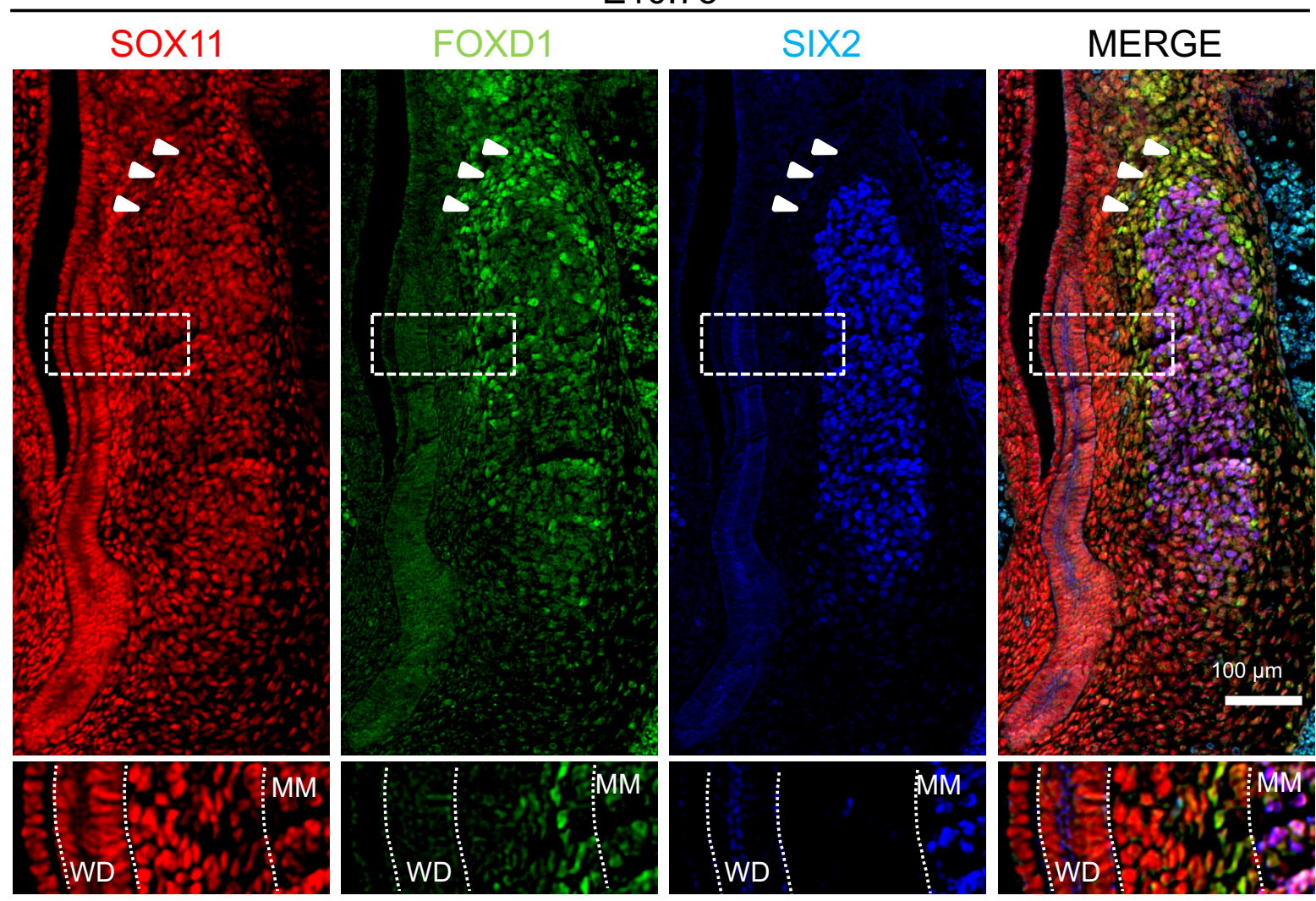

\section{Supplementary Figure 1 : SOX11 expression during kidney development.}

(A) Single channel analysis of figure 1A. (B) Co-Immunostaining of SOX11, FOXD1 and SIX2 at early stage of kidney development (E10.75). SOX11 is co-expressed with the stromal marker FOXD1 only on the edge of the SIX2 positive MM domain (arrowheads) but not in the cells surrounding the WD that are negative for FOXD1 and exterior of the SIX2 positive MM (higher power view, lower panel). WD : Wolffian duct, UB : ureteric bud, MM : metanephric mesenchyme, UT : ureteric tip, CD : collecting duct, CM : cap mesenchyme, $N N$ : nascent nephron, EN : elongating nephron. Scale bars : $200 \mu \mathrm{m}$ and $500 \mu \mathrm{m}$ in (A), $100 \mu \mathrm{m}$ in (B). 


\section{Control}
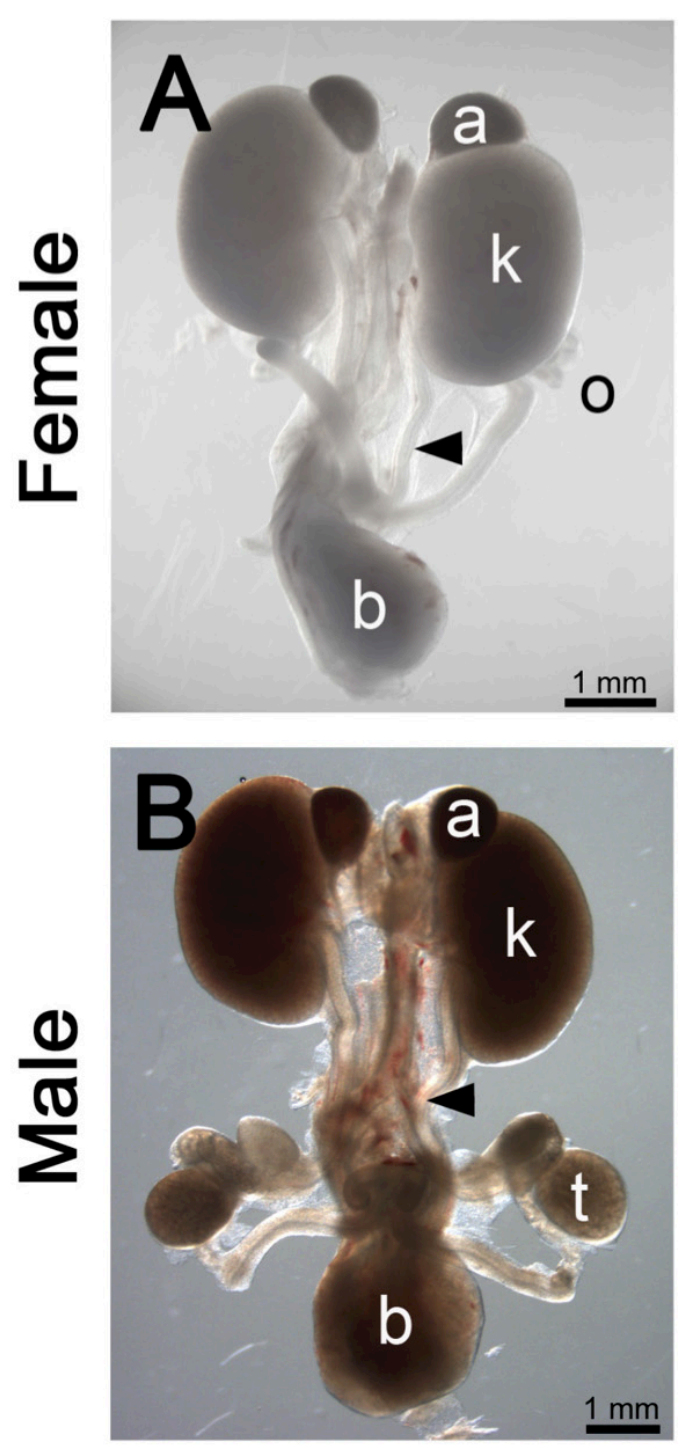

\section{Sox11\%}
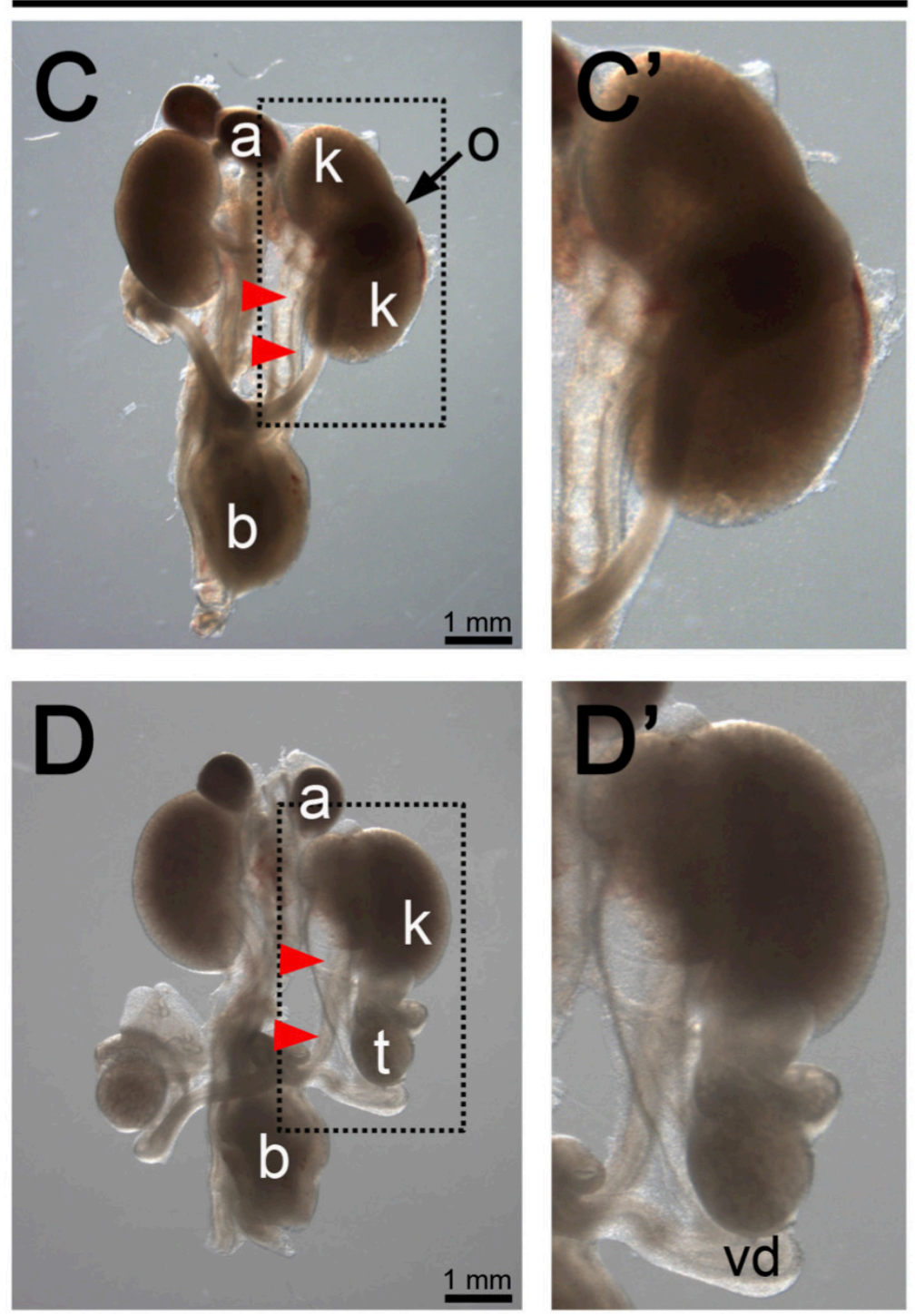

Supplementary Figure 2: Genital tract abnormalities are associated with duplex kidneys in Sox11 knock-out mice.

Urogenital tract of control $(A, B)$ and Sox11 knock-out (C,D) E18.5 embryos. Control female (A) and male (B) urogenital tracts show normal kidneys (k), adrenal glands (a), ureters (black arrowhead), ovary (o) and testis (t). Sox11 knock-out female embryos (C) show duplex kidneys (k) and supernumerary ureters associated with ectopic ovary (o). Sox11 knock-out male embryos (D) show duplex kidneys associated with an hydroureter (red arrowheads) connecting to the vas deferens (vd) and undescended testis (t). Scale bars: $1 \mathrm{~mm}$. 


\section{Control}

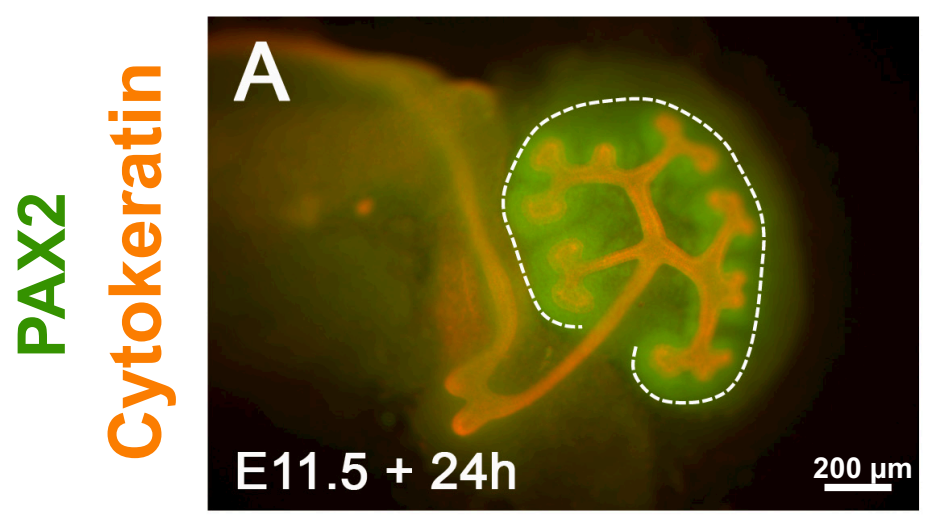

Sox11-

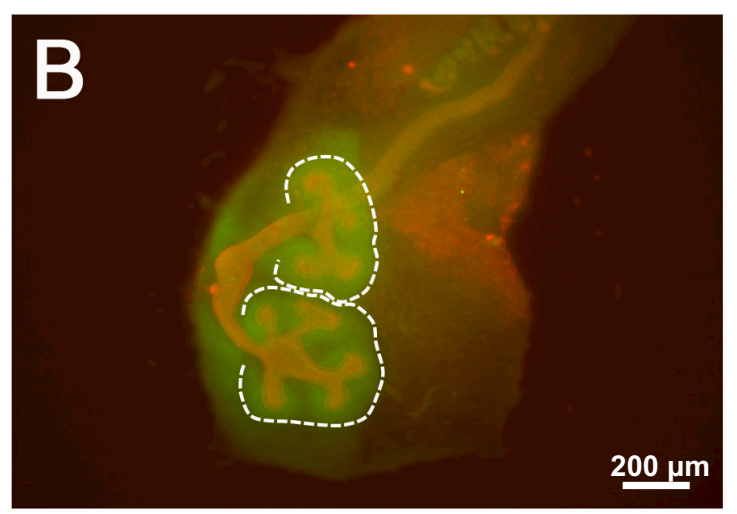

Supplementary Figure 3: Ex-vivo supernumerary bud formation in Sox11 knock-out embryos.

Dissected urogenital ridges of E11.5 Sox11 mutant embryos were cultured for 24 hours and stained with PAX2 and Cytokeratin. A single ureteric bud has emerged and branched in Sox11+/+ embryos (A), whereas two ureteric buds had emerged from the Wolffian duct in the absence of Sox11 (B). Scale bars: $200 \mu \mathrm{m}$. 


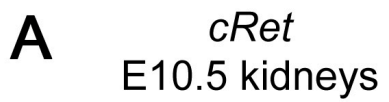

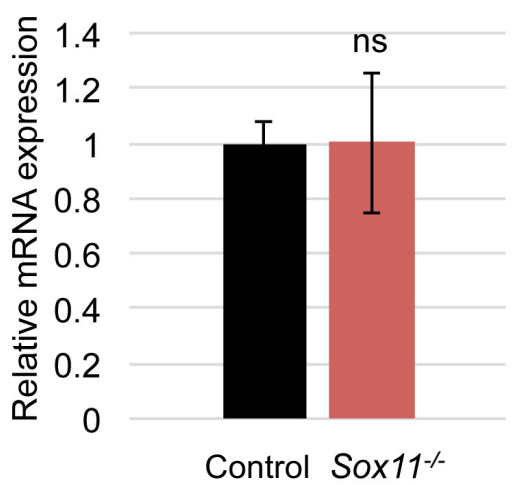

B
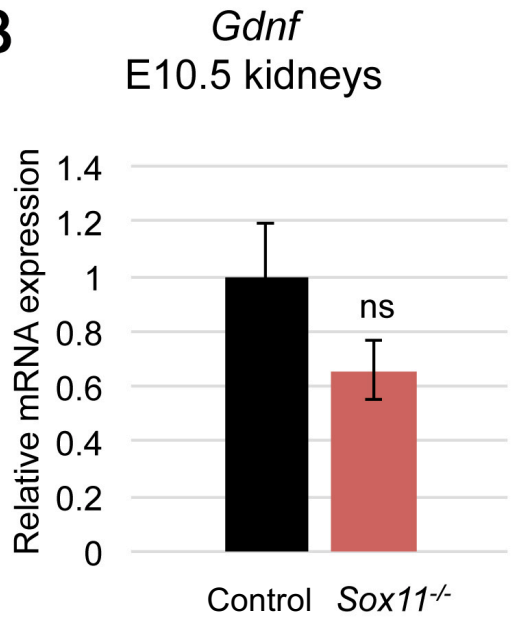

\section{Gdnf}

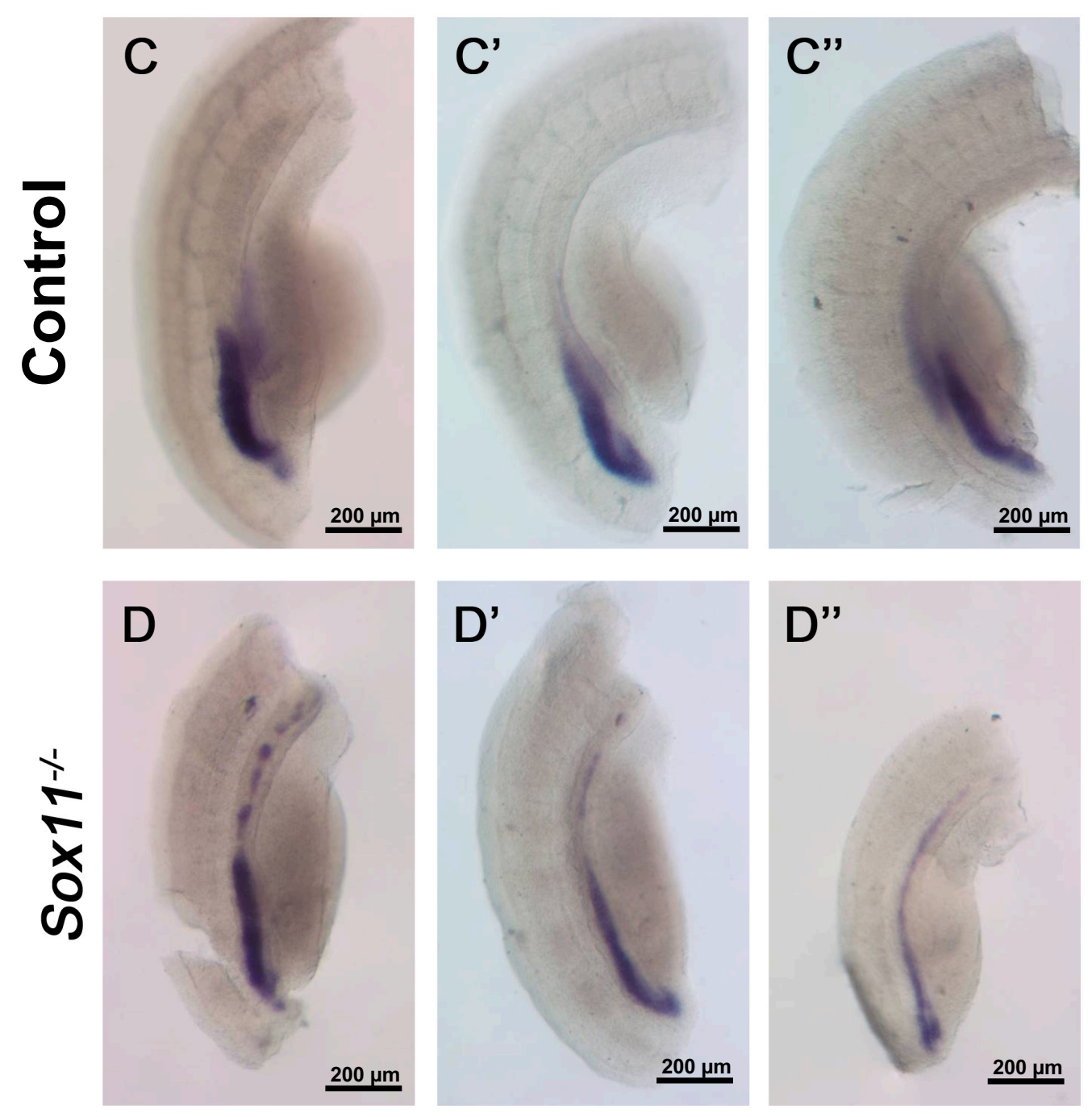

Supplementary Figure 4: Rostral extension of the Gdnf expression domain in Sox11 mutants. $(A, B)$ C-Ret and Gdnf qPCR analysis shows no significant changes in E10.5 Sox11 mutant embryos compared to controls. Data are presented as the average with SEM (ns : non-significant). (C,D) Wholemount ISH on urogenital tracts of E10.75 embryos using Gdnf probe shows a rostral extension of the Gdnf expression domain in Sox11 knock-out embryos. C, C', C" and D, D', D" show different wildtype and Sox11 mutant embryos, respectively. Scale bars: $200 \mu \mathrm{m}$. 

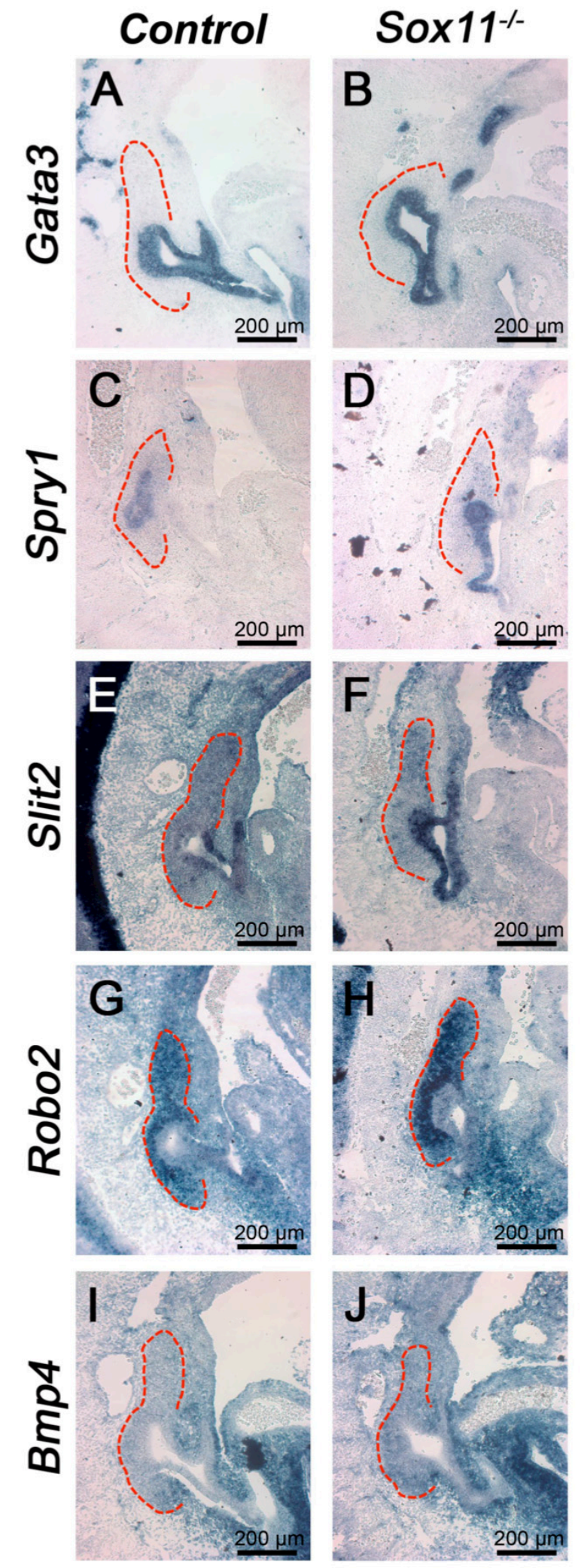

Supplementary Figure 5: Expression of genes known to be involved in ureteric bud outgrowth is not affected by the absence of Sox11.

In situ hybridization at E10.75 of control (A,C,E,G,I) and Sox11 knock-out (B,D,F,H,J) embryos. Gata3 $(A, B)$, Sprouty1 $(C, D)$, Slit2 $(E, F)$, Robo2 $(G, H)$ and Bmp4 $(I, J)$ expression patterns are similar between control and Sox11 mutant. Dotted lines delineate the metanephric mesenchyme. Scale bars: $200 \mu \mathrm{m}$. 
A E17.5

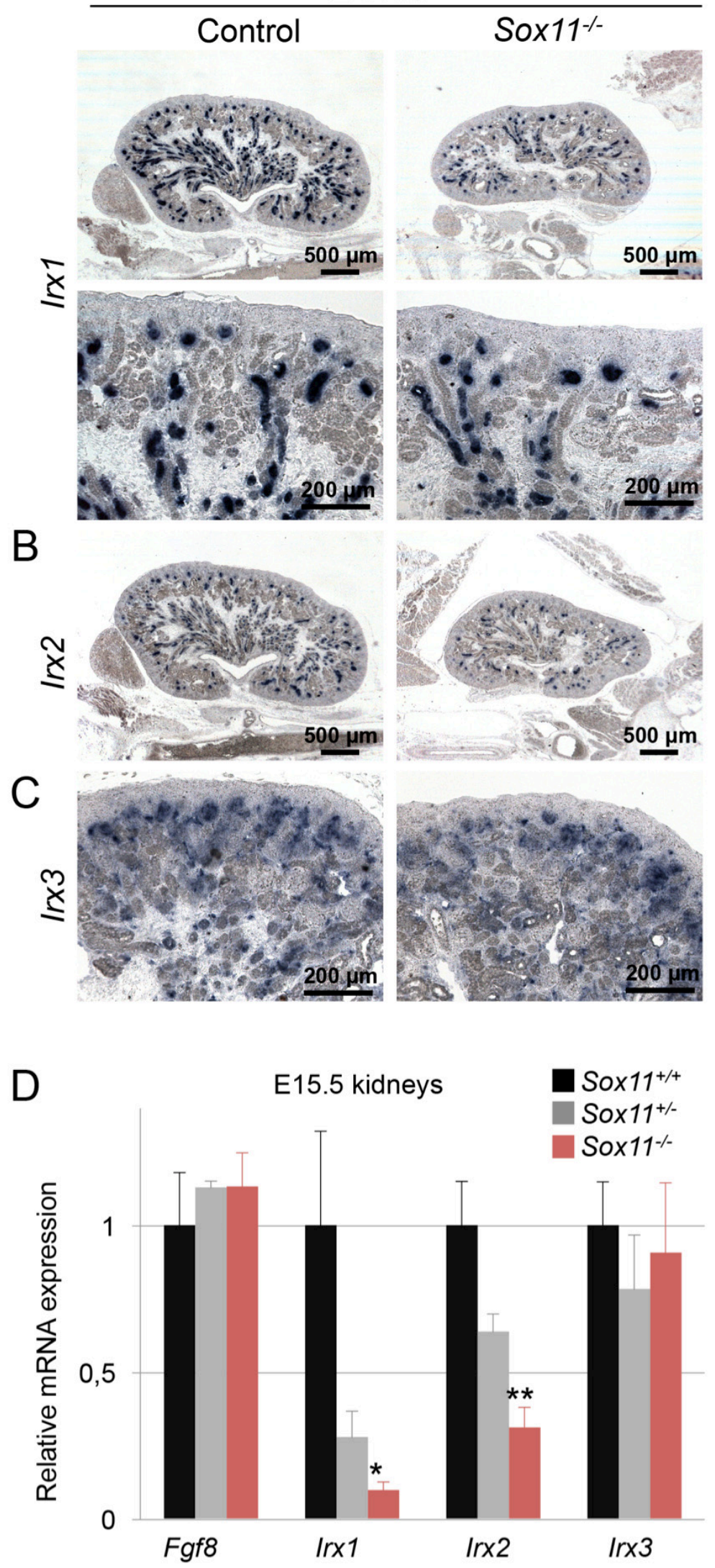

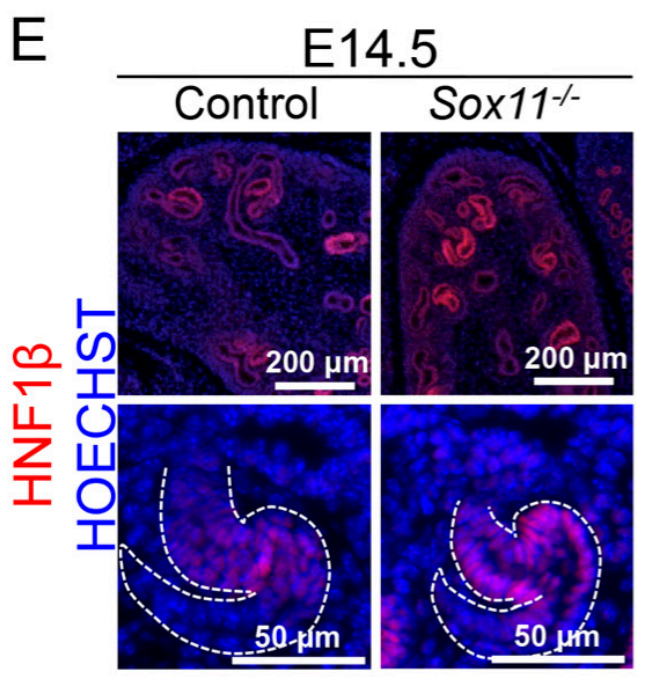
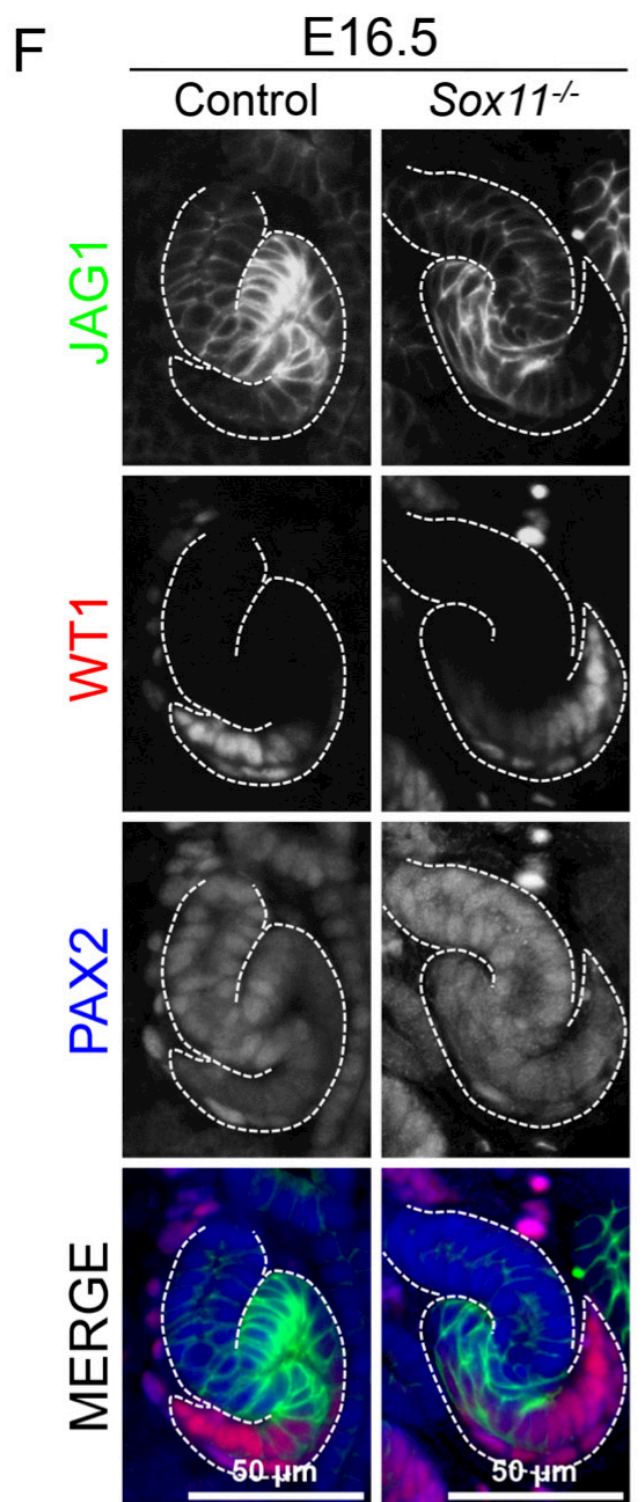


\section{G $\quad$ E16.5}

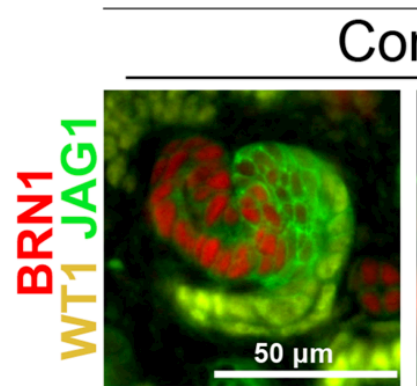

Control
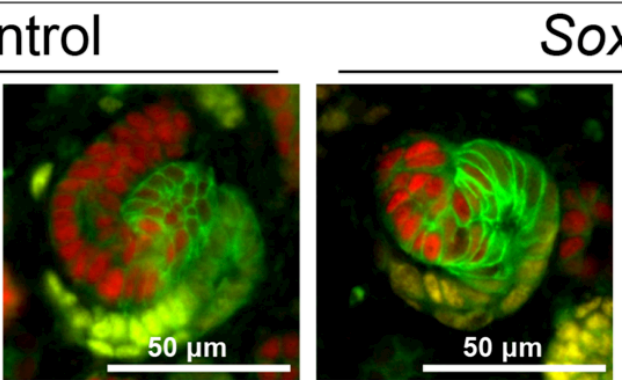

Sox11\%
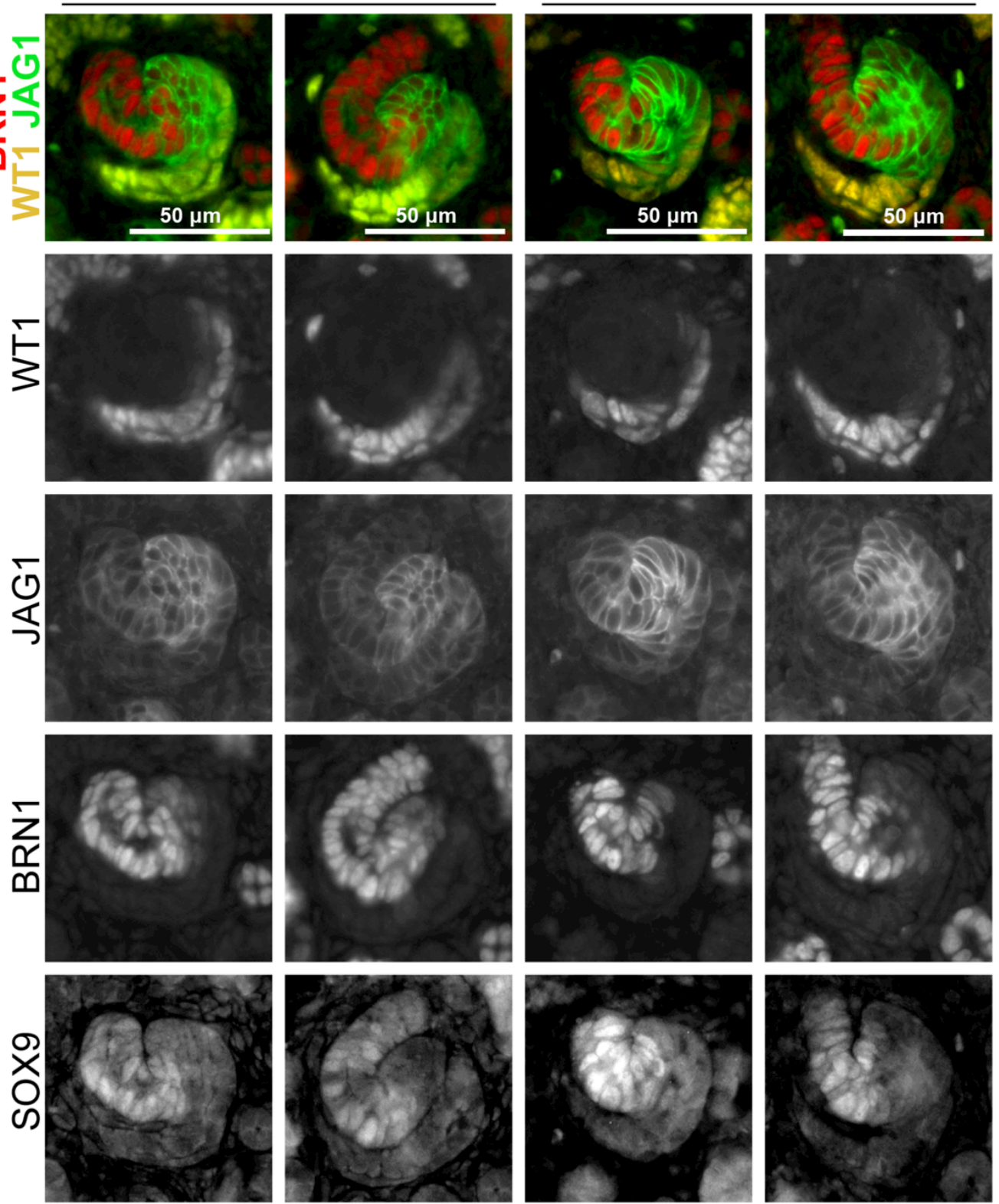

$\mathrm{H}$

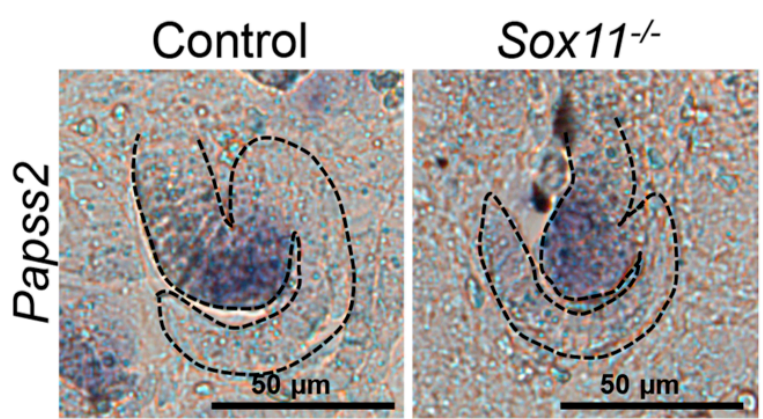

Supplementary Figure 6: Nephron patterning genes are expressed in Sox11 mutants.

(A-C) Expression of Irx1 (A), Irx2 (B), Irx3 (C) is maintained in nascent nephrons of Sox11 mutant mice. (D) qPCR analysis on E15.5 kidneys shows decreased expression levels of Irx1 and Irx2 in Sox11 mutants, highlighting the lack of elongated Henle's loop structures, while Fgf8 and Irx3 levels were unchanged. (E-H) Immunofluorescence and In situ hybridization analyses show that early nephron patterning is maintained in Sox11 mutants. 

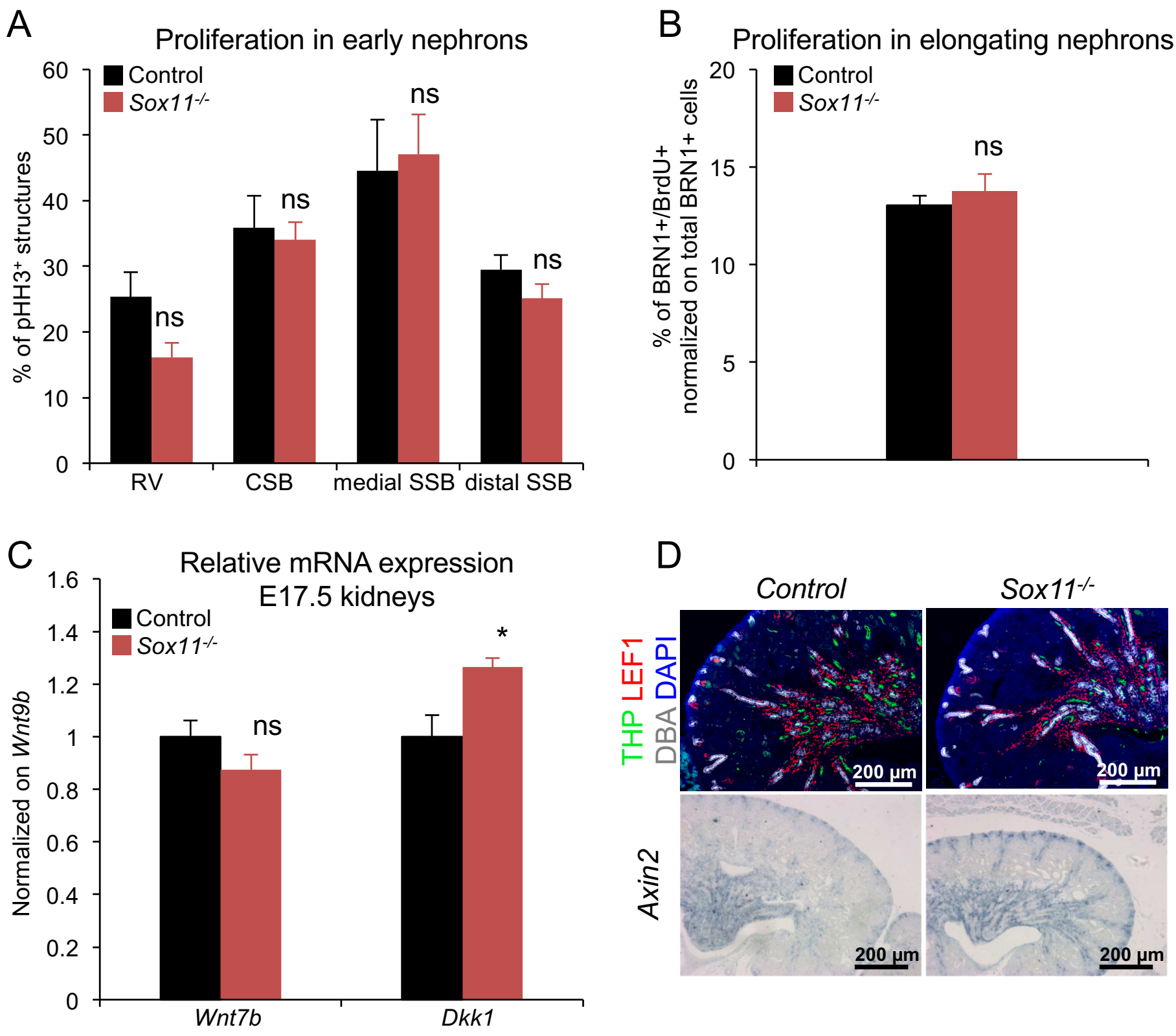

Supplementary Figure 7: Analysis of proliferation and the Wnt/ $\beta$-catenin pathway.

$(A, B)$ No significant change in proliferation rate using the $\mathrm{pHH} 3$ or $\mathrm{BrdU}$ markers were observed in the early nephron structures (renal vesicle (RV), comma (CSB) and S-shaped bodies (SSB)) nor in the elongating loop of Henle. (C,D) qPCR, immunostaining and in situ hybridization reveals no significant changes in Wnt7b, Dkk1, LEF1 and Axin2. Data are presented as the average with SEM ( ${ }^{*} p<0.05$, ns : non-significant). Scale bars: $200 \mu \mathrm{m}$. 


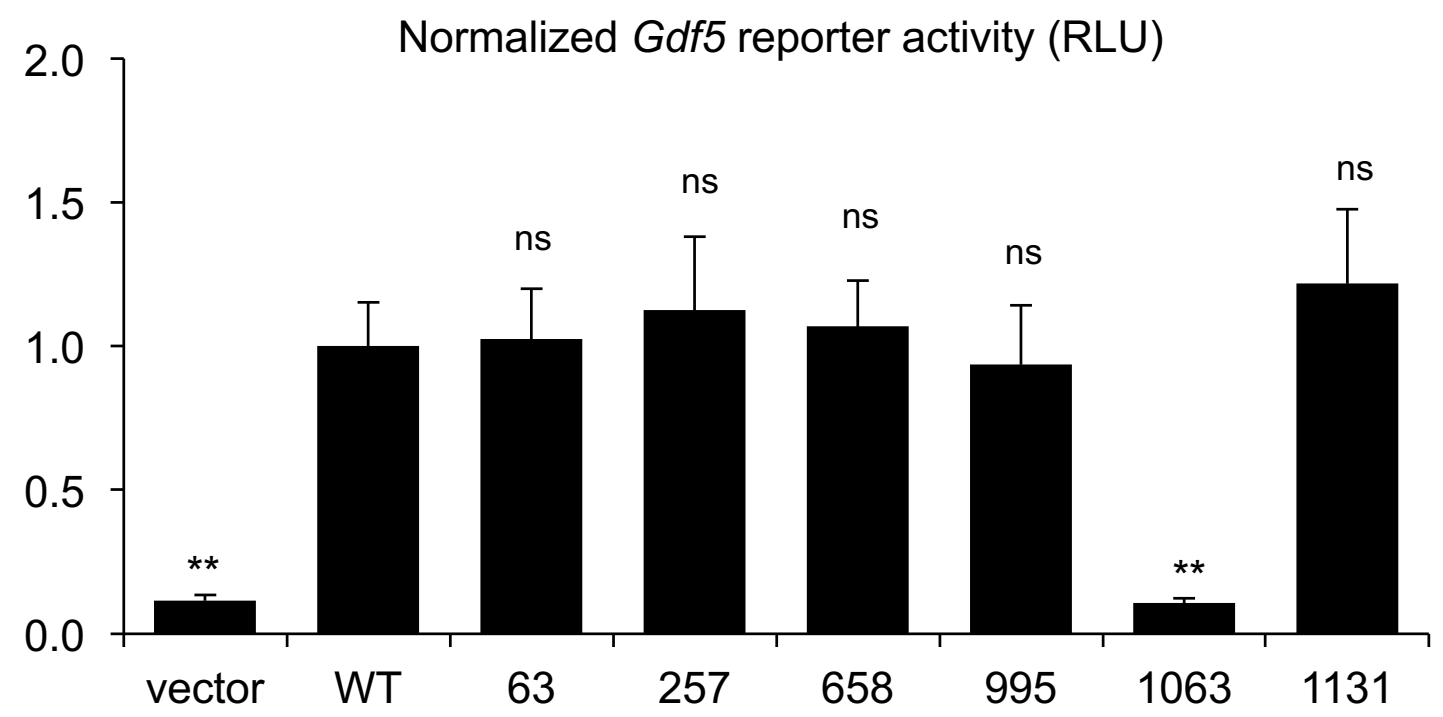

Supplementary Figure 8: Effect of variants on SOX11 trans-activation function in HEK293 cell line.

Transient transfection of HEK293 cells with Gdf5 reporter and expression vectors for wildtype SOX11 (wt), SOX11 variants (numbers corresponding to mutations in the coding sequence) or empty vector. Reporter activities (RLU, relative luciferase units) were normalized for transfection efficiency and on wt condition. Data are represented as the average \pm SEM of three experiments conducted in triplicate. ns: non-significant, ${ }^{* *}: p<0.01$ versus wt (Student t-test). 
Table S1: Number of patients analysed and phenotypic classification

\begin{tabular}{|l|l|}
\hline CAKUT* phenotype & Number of patients \\
\hline Pelvic kidney & 2 \\
\hline Horseshoe kidney & 3 \\
\hline Duplex collecting system & 181 \\
\hline Renal agenesis & 15 \\
\hline Kidney hypo/dysplasia & 51 \\
\hline Multicystic dysplastic kidney & 36 \\
\hline Vesicoureteral reflux & 25 \\
\hline $\begin{array}{l}\text { Ureteropelvic junction } \\
\text { obstruction }\end{array}$ & 136 \\
\hline Hydronephrosis & 14 \\
\hline Obstructive megaureter & 2 \\
\hline Posterior urethral valves & 65 \\
\hline $\begin{array}{l}\text { VACTERL* association with } \\
\text { CAKUT }\end{array}$ & 30 \\
\hline Total & $\mathbf{5 6 0}$ \\
\hline
\end{tabular}

${ }^{*}$ CAKUT, congenital anomalies of the kidney and urinary tract VACTERL, Vertebral anomalies, Anal atresia, Cardiac defects, Tracheoesophageal fistula and/or Esophageal atresia, Renal and Radial anomalies, and Limb defects. 
Table S2 : Antibodies and primers used in this study.

\begin{tabular}{|c|c|c|c|}
\hline \multicolumn{4}{|c|}{ Antibodies } \\
\hline & Dilution & & Producer \\
\hline BRN1 & $1: 1000$ & \multicolumn{2}{|c|}{ Michael Wegner Ref ${ }^{1}$} \\
\hline pan-Cytokeratin & $1: 500$ & \multicolumn{2}{|l|}{ Sigma, C2562, } \\
\hline Cytokeratin 18 & $1: 500$ & \multicolumn{2}{|l|}{ Abcam, ab 52948} \\
\hline DBA & $1: 100$ & \multicolumn{2}{|l|}{ Sigma, L6533 } \\
\hline FOXD1 & $1: 100$ & \multicolumn{2}{|c|}{ Santa Cruz Biotechnology, sc47585 } \\
\hline GFP & $1: 500$ & \multicolumn{2}{|l|}{ Abcam, AB290 } \\
\hline $\begin{array}{l}\text { phospho- } \\
\text { Histone H3 }\end{array}$ & $1: 300$ & \multicolumn{2}{|l|}{ Abcam, ab14955 } \\
\hline JAG1 & $1: 500$ & \multicolumn{2}{|c|}{ Santa Cruz Biotechnology, sc-6011 } \\
\hline LEF1 & $1: 200$ & \multicolumn{2}{|l|}{ Clinisciences } \\
\hline LTL & $1: 200$ & \multicolumn{2}{|l|}{ Abcys, B-1325 } \\
\hline NCC & $1: 200$ & \multicolumn{2}{|l|}{ Millipore, AB3553 } \\
\hline Nephrin/NPHS1 & $1: 200$ & \multicolumn{2}{|c|}{ R\&D Systems, AF3159 } \\
\hline PAX2 & $1: 200$ & \multicolumn{2}{|c|}{ Covance, PRB-276P } \\
\hline Podocin/NPHS2 & $1: 250$ & \multicolumn{2}{|l|}{ Sigma, P0372 } \\
\hline SIX2 & $1: 200$ & \multicolumn{2}{|c|}{ Proteintech, 11562-1-AP } \\
\hline $\begin{array}{l}\text { a-SMA Cy3- } \\
\text { conjugated }\end{array}$ & $1: 1000$ & \multicolumn{2}{|c|}{ Sigma, C6198, 1/1000 } \\
\hline sox11 & $1: 500$ & \multicolumn{2}{|c|}{ Michael Wegner Ref. ${ }^{2}$} \\
\hline THP & $1: 500$ & \multicolumn{2}{|c|}{ AbD Serotec, 8595-0054 } \\
\hline Uromodulin & $1: 500$ & \multicolumn{2}{|l|}{ Meridian } \\
\hline WT1 & $1: 100$ & \multicolumn{2}{|l|}{ DAKO, M3561 } \\
\hline \multicolumn{4}{|c|}{ qPCR primers } \\
\hline Name & \multicolumn{2}{|c|}{ Forward } & Reverse \\
\hline cRet & \multicolumn{2}{|c|}{ TGGAGTTTAAGCGGAAGGAG } & ACATCTGCATCGAACACCTG \\
\hline$D k k 1$ & \multicolumn{2}{|c|}{ CTGAAGATGAGGAGTGCGGCTC } & GGCTGTGGTCAGAGGGCATG \\
\hline Fgf8 & \multicolumn{2}{|c|}{ TCCTGCCTAAAGTCACACAGC } & TGAGCTGATCCGTCACCA \\
\hline Gdnf & \multicolumn{2}{|c|}{ TCCAACTGGGGGTCTACG } & GACATCCCATAACTTCATCTTAGAGTC \\
\hline Irx1 & \multicolumn{2}{|c|}{ GCCCCCACAACAGTTAAAGTC } & CCCCTTAATCAGGCAGACG \\
\hline Irx2 & \multicolumn{2}{|c|}{ GCATTCACTGGCGTCCCACT } & CACAGCCCTCACTGGTATCTT \\
\hline Irx3 & \multicolumn{2}{|c|}{ AGGAGGGCAATGCTTATGG } & TGCTCTCTTCCTCGTCTTCC \\
\hline Wnt7b & \multicolumn{2}{|c|}{ ATGCGGTCCTCCAGAACCT } & TTCTCGTCGCTTTGTGGATG \\
\hline Wnt9b & ATGCGGTC & CAAGACCT & TTCTCGTCGCTTTGTGGATG \\
\hline
\end{tabular}




\begin{tabular}{|l|l|}
\hline \multicolumn{2}{|c|}{ Mutagenesis primers } \\
\hline Mut_SOX11_63_Fw & GGAGGCGCTGGACACTGAGGAGGGCGAATTCATGGC \\
\hline Mut_SOX11_63_Rs & GCCATGAATTCGCCCTCCTCAGTGTCCAGCGCCTCC \\
\hline MutSOX11_257_Fw & AGAGGCTGGGCAAGCTCTGGAAAATGCTGAAGG \\
\hline MutSOX11_257_Rs & CCTTCAGCATTTTCCAGAGCTTGCCCAGCCTCT \\
\hline Mut_SOX11_658_Fw & GACGGTCAAGTGCATGTTTCTGGATGAGG \\
\hline Mut_SOX11_658_Rs & CCTCATCCAGAAACATGCACTTGACCGTC \\
\hline MutSOX11_995_Fw & CGCAGCCCGCGCTGTTGCCCGCGTCCTCGCG \\
\hline MutSOX11_995_Rs & CGCGAGGACGCGGGCAACAGCGCGGGCTGCG \\
\hline MutSOX11_1131_Fw_nv2 & CGCGCACAGCGCCAGTGAGCAGCAGCTGGGG \\
\hline MutSOX11_1131_Rs_nv2 & CCCCAGCTGCTGCTCACTGGCGCTGTGCGCG \\
\hline & \multicolumn{1}{|c|}{ ChIP-qPCR primers } \\
\hline CCR_F & GCACATTTCTACCTCACTCG \\
\hline CCR_R & CCCTTCTCCACCCTTTCCTG \\
\hline Control_F & CCAGCATTTGGGATGTGAAGACTG \\
\hline Control_R & CGTGGCTATTCTGATCCACC \\
\hline
\end{tabular}




\section{Supplementary Methods}

\section{ISH analysis}

Embryos were fixed in $4 \%$ paraformaldehyde in PBS overnight at $4^{\circ} \mathrm{C}$. ISH on section and wholemount ISH were carried out as previously described ${ }^{3}$. Riboprobes for Ret ${ }^{4}$, Gata3 (kind gift from M. Bouchard), Gdnf, Papss2 (kind gifts from F. Costantini and S. Cereghini) ${ }^{5}$, Robo2 \& Slit2 ${ }^{6}, \mathrm{Bmp}{ }^{7}$, Sprouty ${ }^{8}$ and NcC, Nkcc2, S/c5a1, S/c5a2 ${ }^{9}$, were synthesized as described previously ${ }^{10}$.

\section{Histological and immunological analyses}

Embryonic samples from timed matings (day of vaginal plug $=$ E0.5) were collected, fixed in $4 \%$ paraformaldehyde $\mathrm{o} / \mathrm{n}$ at $4^{\circ} \mathrm{C}$, dehydrated and then embedded in paraffin. Microtome sections of $7 \mu \mathrm{m}$ thickness were examined histologically after periodic acid-Schiff staining. For immunofluorescent analysis, dewaxed and re-hydrated sections were treated in $10 \mathrm{mM} \mathrm{Na}$ citrate $(\mathrm{pH} 6)$ for 2 min in a pressure cooker and incubated for 2 hours in 3\% BSA, 10\% normal donkey serum (Jackson Laboratories), $0.1 \%$ Tween20 in PBS). Primary antibodies (Suppl. Table 2) were diluted in 3\% BSA, 3\% normal donkey serum, $0.1 \%$ Tween20 in PBS and incubated overnight at $4^{\circ} \mathrm{C}$. Relevant Cy2-, Cy3- or Cy5-conjugated secondary antibodies (Jackson Laboratories), or AlexaFluor 488-, 594- or 647-conjugated secondary antibodies (Invitrogen), or Biotin-conjugated antibody (Jackson Laboratories, 515-065-003, 1/500) followed by Streptavidin-Cy3 (Sigma, S6402, 1/1000) were used. After mounting (Hoechst, Invitrogen) images were taken on a Zeiss Axio ImagerZ1 (Axiocam MRM camera) and processed with Photoshop. Immunofluorescent analysis on organ cultures was carried out as described previously ${ }^{10}$.

\section{RT-qPCR}

Total RNA was extracted from the dissected caudal area of urogenital ridges of Sox 11 knockout and wildtype E10.75 embryos using the RNeasy MicroKit (Qiagen) followed by column DNase digestion to remove any contaminating genomic DNA. Samples $(n=6)$ were reverse transcribed (M-MLV, Invitrogen) in combination with random primers. qPCR was performed using the TaqMan Master Kit (Roche) and a Light Cycler 1.5 (Roche). Expression levels were normalized for Hprt. Primers were designed on the Roche Universal ProbeLibrary website. Primer sequences are available as Supplementary Table 2.

\section{ChIP-qPCR}

Kidneys were isolated from E14.5 wild-type embryos (OF1, purchased from Charles River) in PBS and kept on ice until dissociation with trypsin (Gibco) at $37^{\circ} \mathrm{C}$. Cells were $1 \%$ formaldehyde-fixed, washed, and nuclei released in lysis buffer (20 mM Tris pH8.0, $85 \mathrm{mM} \mathrm{KCl,} 0,5 \% \mathrm{NP} 40,0,5 \% \mathrm{SDS}$ ) using a $27 \mathrm{G}$ needle. Nuclei were collected by centrifugation, washed and re-suspended in sonication buffer ( $50 \mathrm{mM}$ Hepes pH7.4, 140 $\mathrm{mM} \mathrm{NaCl}, 1 \mathrm{mM}$ Edta, $1 \%$ Triton, 0,1\% NaDeoxycholate, 0.4\% SDS, Protease inhibitor cocktail (Roche)). Chromatin was sheared to an average size of 300-700 nucleotides using a BioruptorPlus sonicator (Diagenode) for $25 \times 30 \mathrm{~s}$. Chromatine was immunoprecipitated with two different SOX11 antibodies (HPA000536, Sigma and kind gift from M.Wegner) or IgG, and protein-A sepharose beads (P3391, Sigma). After extensive washes and elution, chromatine was purified using the QIAquick PCR purification columns (Qiagen) and quantified using the Qubit dsDNA HS Assay Kit (Life technologies). 
For qPCR reactions, same DNA quantities $(25 \mathrm{pg})$ or same volumes (1/50 of the eluats) were amplified with Sybrgreen (Roche) using primers located in the HS19-20 regulatory element of the protocadherin $\beta$ cluster control region (CCR) or in the 3'UTR region of Cd24a gene as a negative control (Table S2). Fold enrichments were calculated using the standard curves method with normalization on IgG.

\section{Reporter assays}

pBluescript plasmid containing coding sequence (kind gift from P. Berta) were used for mutagenesis. Mutations were introduced by site-directed mutagenesis into full-length human SOX11 plasmid using the QuickChange II XL Kit (Stratagene) and primers listed in Suppl, Table 2) and subcloned into pcDNA3.1 expression vector (Life Technologies). The expression vector for the 12 nucleotides insertion variant (mut1063) was a kind gift from A. Morris ${ }^{11}$.

For transient transfection, $12 \times 10^{4}$ HEK293 cells were plated per well of 24-well plates. Mixtures of $50 \mathrm{ng}$ pCMV-Sport-ßgal plasmid (Life Technologies), 50 ng pcDNA3.1-Sox11 expression plasmid, 150 ng Gdf5promoter reporter plasmid ${ }^{12}$ and $0.75 \mu$ FuGENE HD (Roche) were added to the cells 6 hours after plating. $\beta$-Galactosidase and luciferase activities were assayed after $24 \mathrm{~h}$ using the $\beta$-galactosidase Enzyme and Luciferase Assay System (Promega), respectively. Reporter activities were normalized for transfection efficiency.

\section{Supplementary references:}

1. Friedrich RP, Schlierf B, Tamm ER, BosI MR, Wegner M. The class III POU domain protein Brn-1 can fully replace the related Oct- 6 during schwann cell development and myelination. Mol Cell Biol. 2005;25(5):1821-1829.

2. Hoser M, Potzner MR, Koch JM, BosI MR, Wegner M, Sock E. Sox12 deletion in the mouse reveals nonreciprocal redundancy with the related Sox4 and Sox11 transcription factors. Mol Cell Biol. 2008;28(15):4675-4687.

3. Acloque $\mathrm{H}$, Wilkinson DG, Nieto MA. In situ hybridization analysis of chick embryos in whole-mount and tissue sections. Methods in cell biology. 2008;87:169-185.

4. Pachnis V, Mankoo B, Costantini F. Expression of the c-ret proto-oncogene during mouse embryogenesis. Development. 1993;119(4):1005-1017.

5. Heliot C, Desgrange A, Buisson I, et al. HNF1B controls proximal-intermediate nephron segment identity in vertebrates by regulating Notch signalling components and Irx1/2. Development. 2013;140(4):873-885.

6. Grieshammer U, Le M, Plump AS, Wang F, Tessier-Lavigne M, Martin GR. SLIT2-mediated ROBO2 signaling restricts kidney induction to a single site. Dev Cell. 2004;6(5):709-717.

7. Goncalves A, Zeller R. Genetic analysis reveals an unexpected role of BMP7 in initiation of ureteric bud outgrowth in mouse embryos. PLoS One. 2011;6(4):e19370.

8. Basson MA, Akbulut $\mathrm{S}$, Watson-Johnson J, et al. Sprouty1 is a critical regulator of GDNF/RETmediated kidney induction. Dev Cell. 2005;8(2):229-239.

9. Raciti D, Reggiani L, Geffers L, et al. Organization of the pronephric kidney revealed by large-scale gene expression mapping. Genome Biol. 2008;9(5):R84.

10. Reginensi A, Clarkson M, Neirijnck $Y$, et al. SOX9 controls epithelial branching by activating RET effector genes during kidney development. Hum Mol Genet. 2011;20(6):1143-1153.

11. Pillai-Kastoori L, Wen W, Wilson SG, et al. Sox11 is required to maintain proper levels of Hedgehog signaling during vertebrate ocular morphogenesis. PLoS Genet. 2014;10(7):e1004491.

12. Kan A, Ikeda T, Fukai A, et al. SOX11 contributes to the regulation of GDF5 in joint maintenance. BMC developmental biology. 2013;13:4. 